\title{
Chinese Institutions and Policy Experimentation: The case of Zhongguancun
}

\section{By Clinton Watson}

A thesis submitted to the

Victoria University of Wellington

in partial fulfilment of the requirements

for the degree of

Master of International Relations (MIR)

School of History, Philosophy, Political Science and International Relations

Victoria University of Wellington

2013 
The nature of institutional change lies at the heart of understanding China's extraordinary transformation of the past 30 years. This thesis adopts an historical institutionalist approach, emphasising dynamic and path dependent processes, in examining Zhongguancun (ZGC), China's premier science, technology and innovation zone in Beijing. The analytical framework deals with many of the critical issues of institutional analysis of large-scale economic development and social change: the Chinese experience as radical or gradual change; institutional convergence or divergence; formal and informal institutions; top-down design and bottom-up, spontaneous development. ZGC illustrates the ongoing importance of experimentation in Chinese policy as various institutional innovations have emerged from the zone, both spontaneously and through state-led trial schemes. However, increasing preponderance from the Chinese leadership and the highest state-level institutions may ultimately thwart attempts to turn ZGC into a world-class innovation hub. 


\section{Table of Contents}

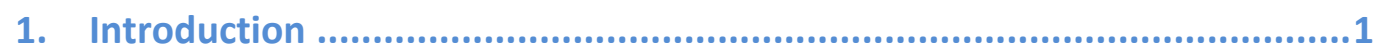

2. Chinese economic reform ......................................................... 3

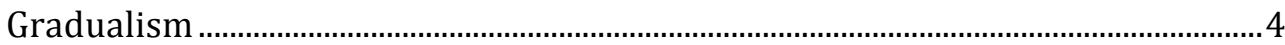

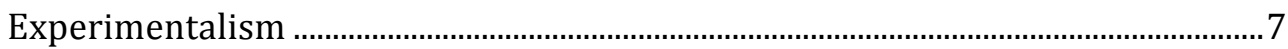

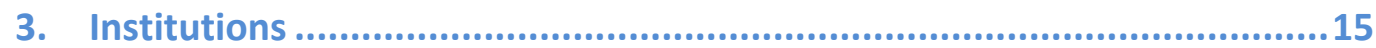

The concept and importance of institutions.......................................................... 15

Chinese institutions - convergence or divergence, a puzzle or not......................17

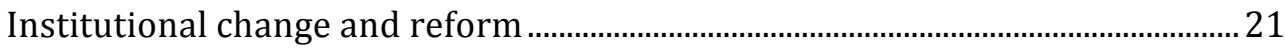

4. Innovation theories and innovation zones .................................... 25

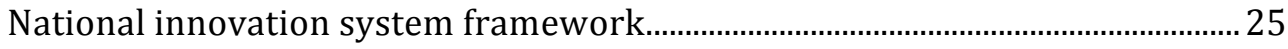

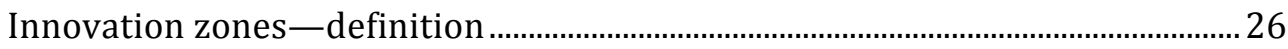

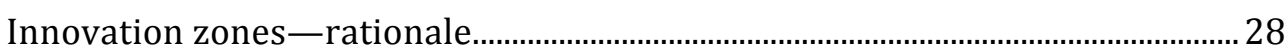

Innovation zones_effectiveness ................................................................................... 32

5. Zhongguancun - development and evolution ....................................36

The context—China's transitional system ………….................................................. 36

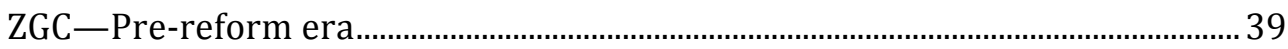

ZGC-Embryonic stages of the zone, 1980-1988 .................................................... 39

ZGC-Formal establishment of experimental zone, 1988-1999 ............................ 41

ZGC-Science and Technology Park, 1999-2009 ....................................................... 45

ZGC-National Innovation Demonstration Zone, 2009-........................................ 50

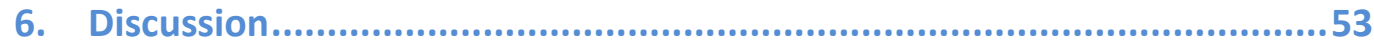

Zhongguancun and Chinese institutions ...................................................................... 53

Innovation zones: Chinese convergence? ……………............................................ 58

7. Conclusion ........................................................................61

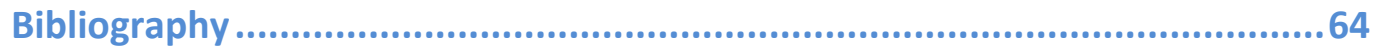

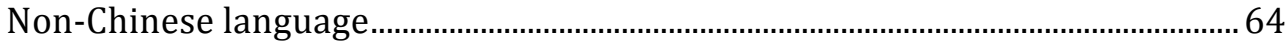

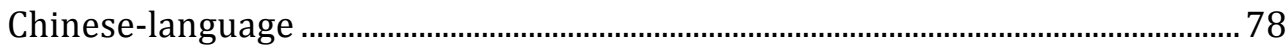




\section{Introduction}

This thesis examines the nature of Chinese institutions and how they develop and evolve, by taking the case of Zhongguancun (ZGC), China's first national-level hightech industrial zone and now a national innovation demonstration zone to the world. The thesis addresses the following questions: "What does the development and evolution of ZGC tell us about how institutions are constructed in China and about policy experimentation in China? How unique or novel is ZGC when compared to other innovation zones in East Asia and OECD economies?"

ZGC serves as a useful case study in understanding the development and evolution of Chinese institutions as well as the use of experimentation in Chinese policy making. First, the formal institutions, including the regulations issued by government authorities, governing the zone have changed periodically. Second, ZGC is an example of a Chinese policy experiment, akin to the special economic zones of Guangdong. The zone was first formally established as an "experimental zone" for high-tech industries and its role in institutional innovation for broader reform in China continues to this day as the State Council encourages "daring reform." Third, ZGC is highly topical and has received much limelight in China, being touted as equal to Shenzhen in the 1980s and Pudong in the 1990s. It is a central plank of China's plans to become a high-value, innovative economy and world science leader.

The findings and conclusions of this thesis lend weight to the historical institutionalist approach, which emphasises dynamic and path dependent processes in institutional formation and development. The thesis begins by examining China's reform, which has been characterised by two key features: gradualism and experimentalism. Combined, these two features have generated pareto-improving institutional change in China. A discussion on Chinese institutions then follows. Chinese leaders have adopted certain prescriptions from standard policy prescriptions, which have been formulated based on Western experience. However, at the same time they have created, or allowed for the creation of, unique institutions suitable to the specific Chinese context and the transition economy. A syncretic approach and high path dependency mark the 
development of Chinese institutions, as opposed to big-bang institutional reforms attempted elsewhere in former command economies.

Theories of innovation highlight the importance of informal institutions, knowledge flows and interactions. In developing countries, including China, informal institutions often play particularly important roles in the absence of formal institutions. Yet in the case of ZGC, informal institutions, trust and collaboration do not appear to be particularly well developed, limiting the zone's effectiveness in producing innovation. A lack of formal institutions, such as a well-functioning intellectual property regime, well-developed capital markets and clear ownership laws, appears to be hindering the development of networks and collaboration.

Finally, the thesis shows that there is a distinct lack of clarity around the concept of innovation areas and science and technology parks, which means that there is no particular institutional setting to which ZGC or Chinese parks could converge. However, it is clear that the experimental role played by ZGC is unique. Its very establishment was an experiment, and bottom-up trials have resulted in changes to the corporate governance of Chinese high-tech firms. Top-down pilot schemes have gained momentum in the last two years with a number of government agencies using ZGC to experiment with innovation policies. The State Council's role is growing and it exercises its power through non-legal institutions, such as speeches and directives. Whether or not ZGC comes to the fore and drives innovation in China through modelling an innovation-inducing institutional framework will depend significantly on the institutional changes dictated from the top, in particular whether they support the development of informal institutions. 


\section{Chinese economic reform}

In 1978, the Chinese economy was the world's tenth largest economy. Today, only the United States economy is larger. ${ }^{1}$ Half a billion people have been lifted out of poverty. ${ }^{2}$ Personal choice has expanded, greater volumes of goods are available, connections with the outside world have increased, and education outcomes have improved. 3 This impressive record has, however, been accompanied by deteriorating income inequality, 4 continued corruption and extensive environmental degradation.

This record stems from fundamental and ongoing reform, which has focused on incentives, mobility, price flexibility, competition and openness. ${ }^{5}$ The Chinese Communist Party has abandoned its former autarkic policies in favour of deep engagement with world markets. The open-door policy has allowed China to move towards labour-intensive production, away from the previous Soviet-type economic strategy which favoured investment in capital-intensive heavy industries. ${ }^{6}$ The Chinese economy is now heavily dependent on global trade ${ }^{7}$ and foreign technology and knowledge.

As a first approximation, China's economy could now be treated as a market economy. ${ }^{8}$ China is generating a form of capitalism as private capital accumulation rises. ${ }^{9}$ However, the Chinese economy is "difficult to pigeonhole because it is simultaneously an intensely competitive market economy and an economy subject

\footnotetext{
1 World Bank (2012a). No country other than China has maintained annual growth of nine percent for more than three decades (Lin 2012).

2 World Bank and Development Research Center of the State Council (2012).

${ }^{3}$ Literacy rates rose from 66 percent in 1982 to 91 percent in 2000 (UNESCO Institute for Statistics). 4 Naughton (2007); World Bank and Development Research Center of the State Council (2012). Since the mid-1990s "economic growth has become increasingly highly regionally driven...and uneven across provinces and regions" (Zhang, J. 2008). Mao adopted extensive redistributive policies, while Deng Xiaoping pursued an uneven development policy inspired by the ladder-step theory (tidu lilun 梯度理论), which recognised the higher levels of productivity and capital in the eastern regions, but higher levels of raw materials, energy and natural resources in western regions. The uneven development policy designated the coastal region to be developed first, followed by the central and western provinces. For a thorough account of China's regional economic development policy and its underpinnings until the mid-1990s see Fan (1995 and 1997). See Tian (2004) for details on the western development programmes.

5 Brandt \& Rawski (2008).

6 Ibid.; Lin (2012).

${ }^{7}$ China's trade ratio has increased from under ten percent prior to reform to more than 50 percent since 2003, a level far higher than either the United States or Japan (calculated from World Bank 2012a).

${ }^{8}$ Chow (2002).

${ }_{9}^{9}$ McNally (2008).
} 
to particularly severe distortions." 10 The transformation from a rigidly planned economy to a market-oriented one is ongoing, mostly because reform of the stateowned enterprise (SOE) sector and financial system has yet to be accomplished. ${ }^{11}$ However, the real challenge ahead is to move China up the value chain through innovation. As Naughton (2007) notes, "[i]nstitutions that support a highproductivity economy are either non-existent or else created very recently and established on shaky foundations." 12

\section{Gradualism}

While the overall impact of China's economic reforms is clear, the exact character of the reforms and the causes of growth have generated lively debate. The camps are divided between those who argue that China has pursued a radical strategy and those who maintain that China has adopted a gradual approach. ${ }^{13}$ The debate centres on the core problem of economic reform, i.e. the transformation of the predominant resource allocation mechanism from the plan to the market. Economic transition involves both reform of the traditional state sector (the core) and the emergence and growth of a nonstate sector (the periphery), consisting of both privately and collectively owned domestic enterprises and foreign invested enterprises. ${ }^{14}$

Those who argue that China has adopted a radical approach point to the dramatic change in development strategy in 1979 when the Chinese government adopted a vigorous reform program. The new strategy centred on expanding enterprise autonomy and building market-based mechanisms. According to this view, China's economic success is due to radical measures introduced rapidly at the end of the 1970s and early 1980s: dismantling of the communes and replacement by household farm plots under various forms of a "contract responsibility system," deregulation of agricultural prices, liberalisation of the township and village enterprises (TVEs) and opening of the coastal regions which brought millions of

\footnotetext{
10 Naughton (2007), p. 10.

11 Land, finance and natural resources are still subject to direct interference and allocation by the state (Lin 2012).

12 Naughton (2007), pp. 10-11.

${ }^{13}$ See Walder (1995) for a useful account of the various views on the interpretation of Chinese reform. 14 Jefferson et al. (1999).
} 
Chinese workers rapidly into an export-oriented labour market. ${ }^{15}$ Subsequent fiscal and tax reforms in the mid-1990s are also held up as radical measures. ${ }^{16}$

The radical school holds that China has achieved the greatest success in precisely the areas where reforms have been the deepest, in particular, in agriculture and in the coastal provinces. ${ }^{17}$ This camp, which includes the international financial organisations and mainstream neoclassical economists, emphasises the rapid and sustained growth of the non-state sector which has introduced a competitive market environment to China. In 1979, the protected industrial sector was effectively opened to new entrants and broad liberalisation allowed for thousands of new TVEs to quickly emerge. This dramatic policy shift and the associated radical measures adopted, particularly in agriculture, account for the rapid growth of the non-state sector.

The gradualist school of thought, on the other hand, argues that China's economic ascent stems from a series of gradual and continuing transitions. There was no rapid price liberalisation, mass privatisation or leap to currency convertibility. This school highlights institutions, competition and government. These theorists 18 emphasise that Chinese planners gradually reduced the size of the planned economy, which allowed a market economy to slowly develop and eventually become dominant. ${ }^{19}$ The Chinese government kept the size of the overall central government materials allocation plan fixed in absolute terms. As the economy was rapidly growing, this meant that the plan became proportionately less and less important until "the economy gradually grew out of the plan." 20 Within this framework, price reform occurred gradually through a dual-track system, whereby a single commodity had both a state-set planned price and a market price. In the early 1980s, a significant proportion of transactions began to occur at market prices, but it was not until 1993 that dual-price came to an end for most industrial products. $^{21}$

\footnotetext{
15 Sachs \& Woo (1997).

16 For instance, in 1994, China unified the exchange rate, issued its first set of company laws and introduced an enterprise income tax (Ibid.).

17 Ibid.

18 Including Chen (1993); Qian \& Xu (1993); Rawski (1995); Naughton (1996); Qian (2000); and Gang \& Woo (2009).

19 Naughton (1996).

20 Ibid., p. 8.

21 Qian (2000), p. 159.
} 
The complexities of Chinese reform mean that neither view is able to accurately capture the entire reform process and China's policy approach. Fan (1994) concludes, "the economic transformation experiences to date do not show either approach to reform, radicalism or gradualism, is unconditionally better than the other." Even Jeffrey Sachs, the architect of several big bang reforms in Eastern Europe, admits that "Chinese reforms were more gradualist or incremental in several other ways." 22 This was particularly the case in the SOE sector where new practices were allowed for a smaller number of SOEs before being more widely adopted over time.23 However, the radical school maintains that the gradualist elements of the Chinese reform agenda slowed growth and that gradualism results "simply from a lack of consensus over the proper course, with power still divided between market reformers and old-style socialists." 24

Thus rather than a polarised reform narrative, a more accurate description is one that recognises Chinese reforms have been both gradual and radical at different stages. For instance, the 1979-83 period represents a typical phase where energetic rapid reform policy was followed by caution. ${ }^{25}$ In the early part of the period enterprises were granted increased autonomy, but this was followed in 1981 by a more conservative position. Between 1993 and 1998 extensive fiscal, corporate, foreign and financial reforms were adopted, but after 1998 the pace of new policy introduction has slowed. Various sectors have also undergone different rates of reform. Agricultural reform was rapid in the early years of the reform period, but urban reform has been markedly slower. China's reform experience has thus been both path-dependent and path-breaking.

Accordingly, Wei-wei Zhang has described China's approach to reform as "dynamic gradualism." This reflects that "the overall guiding philosophy of reform has been gradualist," 26 but that there have also been periods of radical measures. The Chinese expression for this process is "groping for stones to cross the river," (mozhe shitou guo he 摸着石头过河) a metaphor that implies that each step depends on the previous step. Zhang's conception, which straddles the radicalism and gradualism camps, fits well with observations by other China scholars. Chow (2002) notes, "the evolutionary process is considered gradual by those who

\footnotetext{
22 Sachs \& Woo (1997), p. 9.

23 Li (1994); Sachs \& Woo (1997), p. 17.

24 Sachs \& Woo (1997), p. 5.

25 Naughton (1996), p. 97.

26 Zhang (2000), p. 47.
} 
advocate shock therapy as a means of institutional reform, but is in fact very rapid judged by the great adjustments which the Chinese people and institutions have had to make." 27 The overarching emphasis on gradualism also corresponds with the personal accounts of Chinese leaders. Zhao Ziyang in his memoirs writes, "[t]he gradual approach was more stable, less risky, and easier for society to accept."28

Two factors lie behind China's dynamic gradualism: a lack of consensus on the end goal and an absence of a vision of the post-reform economic system. China's reform began without a blueprint for how to reform, and "without even a sense of what the ultimate objective of reform should be." 29 This lies in stark contrast to Poland which, at the outset in 1990, stated its objective was a market economy with a government sector similar in size and function to that found in Western European countries. ${ }^{30}$ The lack of a coherent vision, largely attributable to differing ideological stances as well as vested and conflicting interests, ${ }^{31}$ continues to this day. Chinese leaders have never been able to articulate coherent visions of ownership structure or of a restructured financial system. ${ }^{32}$ This is not to say that the process has been entirely directionless or organically shaped. China's reformist elites have "supplied crucial leadership in the process of reform, especially in providing strategic directions, setting out priorities, reorienting ideology, advancing broad policy initiatives and building pro-reform coalitions." 33

\section{Experimentalism}

In the absence of both a blueprint for reform and political consensus, China's adaptive and gradualist reform has relied heavily on experimentalism. Experimentation aims "to inform policy by using experiments with direct interventions and control groups instead of observational studies or theoretical analyses." 34 Policy experimentation is not simply a matter of unrestricted trial and error or spontaneous policy diffusion, but is instead "a purposeful and coordinated activity geared to producing novel policy options that are injected into official policymaking and then replicated on a larger scale, or even formally incorporated

\footnotetext{
27 Chow (2002), p. 117.

$28 \mathrm{Pu}$ et al. (2009), p. 221.

${ }^{29}$ Naughton (1996), p. 99.

30 Sachs (1993).

31 Sachs \& Woo (1997); Chung (2000); Zhang (2000).

32 Naughton (2007), p. 324.

33 Zhang (2000), p. 3.

34 Mosteller (2006), p. 487
} 
into national law." 35 Accordingly, experimentation means innovating through implementation first, then formulating policy and drafting universal laws and regulations.

The Chinese process of experimentalism, labelled "experimentation under hierarchy," 36 involves policy-makers in central government encouraging local officials to try out new ways of problem solving. Local experiences are then fed back into national policy formulation. If judged to be conducive to Party priorities, "model experiences" (dianxing jingyan 典型经验) are disseminated through extensive media coverage, high-profile conferences, and appeals for widespread emulation. ${ }^{37}$ The Chinese mode of experimentation thus focuses on "finding innovative policy instruments, rather than defining policy objectives, which remains the prerogative of the Party leadership." 38

In China, experimentation occurs in several ways. The first is whereby provisional rules are made for trial implementation. This experimental regulation was particularly prominent in the 1980s and 1990s, but still remains important, notably in rural and welfare reform. ${ }^{39}$ The second approach is "experimental points" or “trials" (shidian 试点) whereby model demonstrations and pilot projects are tried in a specific policy domain. This form has been the most pervasive type of experimentation in the reform era and entails general guidelines issued from the central government which establish guiding thoughts and general demands. The third vehicle for experimentation is experimental zones in which central authorities provide geographic units with broad discretionary powers. ${ }^{40}$

Within this framework, experimentation has taken place at various levels in China and across many sectors:

Twentieth-century experience surely qualifies the Chinese as the world's leading practitioners of economic experimentation. China's reform economy amply displays this penchant for experimentation at every level. We see the national government conducting trials of novel institutions, for example, "special economic zones," while provinces and localities develop their own variations of the household responsibility system, township and village industries, the xiagang system of removing redundant workers from the state enterprise

\footnotetext{
35 Heilmann (2008b).

36 Ibid.

37 Heilmann (2008a); Lin (2012), p. 181.

${ }^{38}$ Heilmann (2008a), p. 3.

${ }^{39}$ Heilmann (2008b).

40 This typology is drawn from Heilmann (2008b).
} 
payrolls, and so on. The decentralization of industry...provided regional and local governments with ample resources with which to pursue such experimentation. ${ }^{41}$

Urban reform in late 1978 was the first instance of policy experimentation in the reform era. Zhao Ziyang allowed six industrial enterprises in Sichuan to produce and market their products after fulfilling the state-fixed quotas. This experiment was soon extended to one hundred firms in Sichuan with the selected enterprises gaining the right to retain a share of profits, sell above-plan output and benefit from accelerated depreciation. ${ }^{42}$ The main feature of the initiative was to delegate decision-making power over the use of investment funds and business activities to local authorities and enterprises. Beijing officially endorsed the Sichuan experiment in 1979 with the programme expanding nationwide.43

Both rural and urban areas have been subject to experimentation. The rural land contract scheme of the 1980s was a central component of rural urban reforms and illustrates the gradual and experimental approach. Zhao Ziyang recalls: "[w]hat form the contracts would take for different industries and enterprises, and how to "contract out" - all of this needed to go through experimentation and proceed gradually." 44 Chinese reformers also encouraged continual urban reform experiments ranging from salary levels, the labour market, the capital market, housing and the social safety net. ${ }^{45}$ For instance, shortly after the Sichuan experiment, reformers initiated an experimental shareholding system that allowed the state, firms and individuals to invest in companies through the purchase of shares. However, in 1987, the state firms were banned from issuing stock to the public, bringing this experimentation to a halt. ${ }^{46}$ After 1992, however, the project resumed and on a much larger scale. 47

Experiments and trials have also been conducted in the SOE sector. In the period 1984 to 1988 , long-term contracting became the predominant form of financial relations within the state sector, but a number of other systems were tried on an experimental basis. While none of these systems was developed enough to be considered major elements of reform, the experimentation "created useful

\footnotetext{
41 Brandt \& Rawski (2008), p. 17.

42 Naughton (1996), p. 99.

43 Qian (2000).

$44 \mathrm{Pu}$ et al. (2009), p. 116

45 Zhang (2000), p. 40.

46 Ibid., p. 57.

47 Ibid., p. 13.
} 
experience for the future." 48 In 1995, local governments in several provinces, including Shandong, Guangdong and Sichuan, began their own programmes of experimentation with the privatisation ${ }^{49}$ of SOEs. The central government later endorsed these experiments through privatising small SOEs. By the end of 1996, up to 70 percent of small SOEs had been privatised in pioneering provinces and about half in many other provinces. 50

The most visible and far-reaching experiment was taken as part of China's opendoor policy. In 1979, Chinese leaders established four Special Economic Zones (SEZs) in China's south. Beijing allowed two provinces, Guangdong and Fujian, to adopt “special policies" (teshu zhengce 特殊政策) and to implement “flexible measures" (linghuo cuoshi 灵活措施) in particular aimed at attracting foreign capital and technology. ${ }^{51}$ They were granted preferential tax measures and enjoyed higher foreign-exchange retention rates. ${ }^{2}$ More importantly, they enjoyed "a special institutional and policy environment and gained more authority over their economic development."53 Local governments put in place efficient regulatory and administrative systems ${ }^{54}$ and provided infrastructure. ${ }^{55}$ The SEZs were given greater decision-making power in a number of areas, especially in approving foreign investment projects. The Shenzhen SEZ was given the greatest freedom to explore innovation, serving as an experimental ground for capitalist policies from 1982.56 Zhang (2000) sums up the experimental role of the SEZs:

The SEZs became, effectively, laboratories in which the operation of the market economy was carried out. The intention of the state was to extend methods that proved successful in the zones to other parts of the country. Should the experiment fail, its adverse impact could be minimized since the zones were located far away from China's political and economic centres. The strategy was relatively successful

\footnotetext{
48 Naughton (1996), p. 218.

49 Instead of "privatisation," the Chinese use terms such as "transformation of ownership" (zhuanzhi 转制) or “restructuring of ownership" (suoyouzhi gaizao 所有制改造).

50 Qian (2000), p. 164.

51 Yeung et al. (2009).

52 Fan (1995); Zhang (2000).

53 Qian (2000), p. 155.

54 Government officials in Shenzhen admit openly that the reduction in bureaucratic paperwork and the facilitation of the requisite approvals were more important to creating a favourable environment than the preferential tax treatment (Qian \& Stiglitz 1996).

55 Zeng (2010).

56 Chow (2002); Yeung et al. (2009). Shenzhen innovations include land tenure reform, price system reform, labour market reform, financial system reform, and reform of state-owned enterprises (Yuan et al. 2010).
} 
in attracting foreign capital, pioneering reform experiments and creating from scratch an export-oriented economy. ${ }^{57}$

The success of the initial SEZ experimentation led to the opening up of 14 coastal cities in 1984. Beijing permitted local authorities to set up Economic and Technological Development Zones (ETDZs) and to arrange a certain amount of foreign investment without central government approval.58 In 1985, "open coastal economic areas" were designated in the Zhujiang (Pearl), Minnan and Yangzi deltas, and in Liaodong Peninsula and Shandong Peninsula in 1987. Preferential policies were granted to these areas, but they were less favourable than in the SEZs and ETDZs. Rounding out this second phase of the initial experiment, Hainan Island was declared a province in 1988 and allowed to adopt the same favourable policies as those of the SEZs.

The third stage of the open-door experiment was to establish the Pudong (Eastern Shanghai) New Zone in 1990. The zone offered preferential treatment to foreign investment on a par with, or more favourable than, that on offer by the SEZs. In 1992, most cities along the Yangzi River and China's borders were also granted special privileges as coastal cities. In addition, Shanghai was granted even greater autonomy and the central government allowed experiments in retail and other service sectors. ${ }^{59}$ Many inland cities, which did not qualify as either special economic zones or coastal open cities, established development zones to take advantage of the tax benefits and increased autonomy. Many of these developments took place without approval from the central government.60 Between 2000 and 2002, seventeen additional ETDZs were established in the interior of China as part of the Western Development Program.61 By 2010, there were 69 state-level ETDZs throughout China, most located in the suburban regions of a major city. ${ }^{62}$ Due to their increased number, the zones are less special than before, but "the rules of business are still subtly different inside the zones." 63

The spread of China's economic zones has resulted in the borders around the zones being steadily broken down as more of the country has opened up to trade and

\footnotetext{
57 Zhang (2000), p. 20.

58 This varied according to the zone. Shanghai and Tianjin were granted authority to approve foreign investment up to $\$ 30$ million, Dalian up to $\$ 10$ million, and the remaining 11 cities up to $\$ 5$ million (Qian 2000: 158).

59 Naughton (2007), p. 409.

60 Qian (2000).

61 Naughton (2007), p. 410.

62 Zeng (2010).

63 Naughton (2007), p. 406.
} 
investment. The zones have allowed space to experiment with much of the legislation that now governs China's modern economy and work force relations. ${ }^{64}$ What started off as an experiment has been gradually rolled out, with the result that the zones and their associated policy measures have become pervasive throughout many areas of China. China's development zones have "accomplished their historical mission of serving as experimental areas for the implementation of open policy in China." 65 Of most importance, the SEZs have been a significant engine of development, accounting for disproportionate shares of growth, foreign investment and employment.66

However, not all Chinese experiments have worked. Experimentation will by definition lead to success and failure. One example of the latter is experimentation in the financial sector, where "financial and institutional innovation has been nearly continuous since the 1980s." ${ }^{67}$ However, these experiments have mostly failed and new institutions have not yet been allowed to play the dynamic and independent role that would be expected of financial institutions in a market economy. For instance, domestic trust companies were cut back sharply in the mid1990s, enterprise investment companies have been subject to increasing control, and successful urban credit cooperatives have been captured by municipal governments and converted into "City Banks." 68 In contrast to other areas, experimentation in the banking sector has been largely unsuccessful as government agencies and government-linked companies remain dominant. ${ }^{69}$

The above examples show that experimentation has been a key feature of China's policy approach. This modus operandi has allowed reformers to initiate experiments for reform in controversial areas. Ideas have been generally encouraged, so long as they contribute to building a more dynamic economy. Zhang (2000) notes, "[i]f the initiatives are controversial, they are in most cases tolerated as experiments." 70 Experimentation has also been used as a guise to pursue and extend reforms. Household farming, for example, was still labelled an "experiment" when it had spread across a third of China's countryside. Zhao Ziyang succeeded in extending his experimentation with the responsibility system to 94 percent of

\footnotetext{
64 Saich (2000).

65 Wong \& Tang (2005), p. 314.

66 Zeng (2010).

67 Naughton (2007), p. 451.

68 Ibid.

${ }^{69}$ Heilmann (2008b).

70 Zhang (2000), p. 70.
} 
Guangdong's enterprises in less than a year, despite a consensus in Beijing to reign in decentralisation. ${ }^{71}$

Beijing has allowed provincial governments to experiment with different reform measures which partly explains the large variations in reforms from province to province. ${ }^{72}$ Regional experimentation is feasible and less costly in China than in the other transition economies due to weaker regional interdependence. ${ }^{73}$ As a large country with less heterogeneity, "large scale regional experiments can be carried out, many regions have a chance to develop a large variety of 'mutants,' and the central government may be able to compare and select among various alternatives."74 This combined with the fact that adjacent regions have similar economic structures mean that successful experiments can be easily promoted in other regions. ${ }^{75}$ Learning by experimentation avoids information overload and allows the government to learn what kinds of decisions can be decentralised without disruptive costs, who would carry out what types of experiments, and what new institutions should be rolled out extensively. ${ }^{76}$ Thus, experimentation appears to allow for efficient reform in China. Zhao Ziyang's account of the delegation to local authorities is particularly instructive:

\begin{abstract}
Since the power to choose was given to local leaders and cadres, and they were given time to make their choice (time enough to shift from unwilling to willing), the shifts occurred voluntarily. This reduced the possibility of conflicts and negative effects. It gave local authorities enough time to make a choice, to realize the superiority of the schemes and to figure out how to adopt them to their own development conditions. As it moved from the poorest regions to average and wealthier ones, the policy was gradually perfected. ${ }^{77}$
\end{abstract}

WTO rules have placed restrictions on experimental regulations in the SEZs. To conform to the principle of national treatment, the Chinese government is committed to gradually removing preferential tax breaks and other privileges for foreign investment.78 Such an adjustment will place Chinese enterprises in a better position to compete with foreign companies. ${ }^{79}$ In tandem, the Communist Party is increasingly emphasising law-based policy implementation, limiting the use of

\footnotetext{
71 Ibid., p. 69.

72 Qian \& Xu (1993), p. 154.

73 Ibid.

74 Ibid., p. 151.

75 Ibid.

${ }^{76}$ Qian \& Stiglitz (1996), p. 187.

$77 \mathrm{Pu}$ et al. (2009), p. 143.

78 Hsiung (2003).

79 Wong \& Tang (2005).
} 
experimentation which places implementation before policy. Yet, despite these constraints and trends, experimentation continues in China. 80

In summary, in the absence of political consensus and a theoretical framework, Chinese leaders have allowed for frequent experimentation. This openness to controversial ideas, particularly at the regional level, has been a central component of China's overall guiding philosophy of gradualism. The most symbolic example of China's experimentalism and gradualism is the establishment of the Special Economic Zones which were given latitude to try out various reforms within a framework of special financial, investment and trade privileges. Upon demonstrating success, various reform measures were rolled out to the point that the pioneering policies of the SEZs are now by and large the norm throughout China. Policy experimentation has enabled Chinese leaders to engage in institutional innovation, involving bottom-up initiatives and the incorporation of local knowledge into the national policy process. The list of successful experiments is extensive, including the household responsibility system, dual-track pricing, township and village enterprises and the special economic zones. ${ }^{81}$

80 Heilmann (2008b).

81 Rodrik (2008), p. 30. 


\section{Institutions}

The nature of institutional change lies at the heart of the analysis of transition and transformation, and ultimately of economic growth and development. It therefore takes centre stage in the scholarly debate on Chinese reform and the causes of growth. The incremental school tend to argue that China has been evolving towards a unique set of economic institutions, partly as a result of experimentalism in policy design. The school of thought in favour of the big bang approach argue that China is harmonising its economic institutions with those of other market economies.

\section{The concept and importance of institutions}

The theoretical basis for the importance of institutions in economic development can be traced back to Adam Smith. While stressing the primacy of capital accumulation, Smith pointed to savings determining the rate of capital accumulation and that savings ultimately depended on the social and legal framework. Of China, Smith wrote that it "seems to have been long stationary, and had probably long ago acquired that full complement of riches which is consistent with the nature of its laws and institutions [emphasis added]." 82 Smith thus recognised that the institutional framework underpinned growth, or limited it in the case of China.

The centrality of institutions to development, however, was not extensively recognised and theorised until North and Thomas' (1973) seminal publication, which argued that the establishment of formal institutional arrangements and property rights accounted for the rise of the West. They argued that innovation, economies of scale, education and capital accumulation are not causes of growth, but are growth. For growth to occur, efficient economic organisation was required that enticed individuals, through incentives, to undertake socially desirable activities. Institutions control or reduce transaction costs, i.e. the costs of economic exchange, such as search and information costs, access costs, policing and enforcement costs and bargaining costs. ${ }^{83}$

The institutional framework that unfolded in England laid the basis for the Industrial Revolution by providing for efficient organisation of economic activity. It

82 Smith (1776/1991), p. 84

83 Coase (1937). 
encouraged innovation and technological change, which is what accounts for growth in the long-term, according to new growth theories. ${ }^{84}$ Accordingly, there is now an international consensus on the importance of institutions to economic development. Institutional reforms are now recognised as essential in enhancing long-term economic growth. ${ }^{85}$ Institutional settings in East Asia have been particularly important in generating that region's rapid economic growth. ${ }^{86}$

North (2005) defines the institutional framework as consisting of the "political structure that specifies the way we develop and aggregate political choices, the property rights structure that defines the formal economic incentives, and the social structure-norms and conventions-that defines the informal incentives in the economy." 87 Institutions thus structure "the way the game is played" and "reduce uncertainty by providing a structure to everyday life." 88 In doing so they reduce transaction costs, which arise from the bounded rationality and opportunism of the transacting parties. 89

Formal rules, informal norms and their enforcement characteristics are all part of this framework. Formal institutions can be interpreted narrowly as comprising strictly legal institutions of the state, such as constitutions, laws and regulations or more broadly as rules and procedures that are official and openly codified, including organisation rules. ${ }^{90}$ Informal institutions embody the moral codes of a society's belief system and the norms and conventions particular to individual societies. ${ }^{91}$ They are "socially shared rules, usually unwritten, that are created, communicated, and enforced outside of officially sanctioned channels." ${ }^{92}$ Both sets of institutions complement one another and form the institutional setting of a particular context.

According to North (2005), an institutional framework "reflects the accumulated beliefs of the society over time, and change in the institutional framework is usually an incremental process reflecting the constraints that the past imposes on the

\footnotetext{
84 The seminal publications in new growth theory, also known as endogenous growth theory, include Romer (1986) and Lucas (1988).

85 Burki \& Perry (1998); Easterly \& Levine (2001 and 2003); Rodrik et al. (2002); and Acemoglu et al. (2005). Glaeser et al. (2004) present a dissenting view, highlighting the importance of human capital over institutions.

86 Rodrik (1998); Huang (2008).

87 North (2005), p. 49.

88 North (1990), p. 3.

89 Williamson (2000).

90 Helmke \& Levitsky (2004).

${ }^{91}$ North (1990).

92 Helmke \& Levitsky (2004), p 727.
} 
present and the future." 93 Change in the institutional framework is typically incremental due to path dependency brought about by "the severe constraints on the choice set of entrepreneurs when they seek to innovate or modify institutions in order to improve their economic or political positions." 94 Simply put, large-scale change creates too much opposition since many players in existing organisations will be affected. Thus, an analytical framework focusing on institutions fits neatly with the gradual approach to Chinese reform given the emphasis on incremental change.

\section{Chinese institutions-convergence or divergence, a puzzle or not}

The Chinese economy presents a unique case to test what institutions are essential for economic growth and development. The big-bang school of thought argues that China is harmonising its economic institutions with those of other market economies. China has opened up its economy, maintained fiscal stability, reduced the size of the state sector, embraced competition and is developing legal institutions and the rule of law. Institutional experimentation is not needed or desired since "the long-run goals of institutional change are clear, and are found in the economic models of existing market-based economies." 95 This view is widely held: "[i]nternational organizations, local policy makers, and private consultants combine to enforce the presumption that the most advanced countries have already discovered the one best institutional blueprint for development and that its applicability transcends national cultures and circumstances." 96 Even some scholars who see China's success as due to its gradualism, concede that Chinese institutions are "becoming more similar to those in other countries," although they insist that China's economy "retains distinctive institutions." 97

The incremental school tend to argue that China has been evolving towards a unique set of economic institutions, partly as a result of experimentalism in policy design. This camp stresses that China, like other highly successful economies, such as those of South Korea and Taiwan, has combined unorthodox elements with orthodox policies. The performance of Latin American economies, on the other hand, has been disappointing, despite their implementation of "first-best"

\footnotetext{
93 North (2005), p. 49.

94 Ibid., p. 2.

95 Sachs \& Woo (1997), p. 5.

96 Evans (2004), p. 33.

97 Naughton (2007), p. 5.
} 
policies. ${ }^{98}$ The essential point of the incremental school is that China has experienced rapid growth, but without many institutions conventionally regarded as essential, such as the rule of law, secure property rights, effective corporate governance or transparent financial systems. ${ }^{99}$ China's reforms have departed significantly from standard prescriptions with "partial liberalization, two-track pricing, limited deregulation, financial restraint, an unorthodox legal regime, and the absence of clear private property rights." 100 International governance indicators, with the exception of government effectiveness, show that Chinese institutions rank in the bottom $50^{\text {th }}$ percentile.101 Rule of law remains weak and confused with the legal system unable to perform the task of enforcing the rules of economic reform in many crucial areas, including investor protection systems, corporate governance and accounting standards. ${ }^{102}$

The establishment of clearly assigned, private property rights, was a central, if not the central, institutional innovation in North and Thomas' account of the rise of the West. Property rights refers to an owner's right to use a good or asset for consumption and/or income generation, to transfer the right and the right to contract with other parties. ${ }^{103}$ The experience of China adds, however, some nuance to their premise. The general consensus is that property rights remain weak in China. ${ }^{104}$ Extensive research by Peter Ho (2005) shows that land property rights remain unclear and uncertain. Land in China has not been adequately registered and no systematic cadastre has been developed. The repeated requisitioning of land for the use of development has been made possible in part by China's unclear landed property rights. ${ }^{105}$ Villagers are uncertain about the rights they enjoy to land as "there are no regulations governing the free transfer, sale, and mortgage of rural land."106 Furthermore, land ownership is still firmly in the hands of the state and the collective, not the individual. ${ }^{107}$ Even in cases where property rights are clearly defined, the legal system is often unable to enforce property rights effectively. This does not, however, mean to say that property rights do not matter.

\footnotetext{
98 This is particularly the case of Argentina (Evans 2004: 35).

99 Qian (2003).

100 Mukand \& Rodrik (2005), p. 374.

101 World Bank (2012b).

102 Clarke (1996); Haggard (2004); Feng (2011); and Li (2011). For instance, laws and regulations are promulgated by a wide variety of governmental and quasi-governmental bodies and no comprehensive indexes are available.

103 Barzel (1989).

104 Heston \& Sicular (2008).

105 Huang, P. (2011).

106 Ho (2005), p. 125.

107 Ibid.
} 
Several studies show that property rights in China can be protected through informal institutions and that local governments can enforce rights. 108

This apparent paradox of high growth and unconventional institutions is sometimes referred to in the literature as the "China puzzle." 109 Simply put, Chinese growth is too high relative to its institutional development.110 The notion of a "China puzzle" rests on the assumption that there exists a set of best practice institutions, modelled after liberal Western economies. ${ }^{111}$ While there has been a convergence of views over the last several decades as to the set of economicenhancing policies, ${ }^{112}$ economic performance is more heterogeneous around the globe than it has ever been. ${ }^{113}$ Recent research shows that first-order economic principles such as incentives, competition, fiscal sustainability and property rights do not translate directly into unique institutional settings. ${ }^{114}$ For instance, a competitive environment can be sustained through either a well-functioning regulatory authority or through a combination of free entry and laissez-faire. A convergence on western institutions should not therefore be taken for granted, given local contexts with varying histories, geographies, cultures and norms. Consequently, the notion of a "China puzzle" is a misnomer as China has generally embraced first-order economic principles.

There is thus a growing recognition that, beyond first-order principles, there is no set formula for achieving economic development nor is there one economic model that can capture the intricacies of economic growth in a particular society. What we once considered "alternative economic institutions" can therefore serve a market economy.115 North (2005) notes the following:

It should be emphasized that the institutions that have emerged in the Western world, such as property rights and judicial systems, do not have to be faithfully copied in developing countries. The key is the incentive structure that is created, not the slavish imitation of western institutions. Starting with the household responsibility system, the Chinese developed an

\footnotetext{
108 Nee \& Su (1996); Ho (2005); and Krug \& Hendrischke (2006).

109 See, for instance, Qian (2003); Huang, X. (2011).

110 Burki \& Perry (1998).

111 Qian (2003).

112 The "Washington Consensus," shared by the Washington-based international financial institutions, has been the most influential, but also controversial, reform agenda. It proposes ten policy instruments as necessary for growth: fiscal discipline; public expenditure priorities in education and health; tax reform; positive but moderate market-determined interest rates; competitive exchange rates; liberal trade policies; openness to foreign direct investment; privatisation; deregulation; and protection of property rights (Williamson 1990).

113 Mukand \& Rodrik (2005).

114 Ibid.

115 Chow (2002), p. 391.
} 
incentive structure which managed to produce rapid economic development without any of the standard recipes of the West. ${ }^{116}$

Successful institutional reform has often not involved the direct copying of best practice institutions.117 Instead, "experimentation is required to discover what works locally"118 as institutions exhibit a high degree of specificity. A number of prominent scholars have argued that policy experimentation can be an effective mechanism to find out what works on the ground, to induce behavioural changes and to produce institutional innovations that are conducive to entrepreneurialism, investment and growth. ${ }^{119}$ Owing to a lack of information as to what works, tailoring of principles to specific contexts through experimentation and policy diversity, backed up with robust monitoring and evaluation, is required.120

As demonstrated in the previous section, experimentation has been a key feature of Chinese reform and its policy approach. Experimentalism has led to a variety of transitional institutions emerging, many of which took unconventional forms. They could be labelled as "second-best arrangements" but they were quite effective in providing incentives.121 Privately owned enterprises played a minor role in the economy in the first 15 years of reform, yet growth was high. By 1991, collectives and joint ventures were the dominant majority of the non-state sector.122 The TVEs were a key driver of Chinese growth between 1980 and $1995^{123}$ yet this institutional innovation formed no part of standard policy prescriptions and ran counter to the property rights thesis. Property rights were not clearly defined and they operated in an environment without the protection of a modern legal system. The TVEs were a solution to the problem of weak market structures and incomplete market transition. ${ }^{124}$

Experimentation can thus lead to unusual institutions when viewed against "firstbest" solutions. However, these unorthodox institutions may well be the best response to the particular national and regional context, local culture and existing institutions. Developing countries tend to rely heavily on informal institutions

\footnotetext{
116 North (2005), p. 159.

117 Qian (2003).

118 Mukand \& Rodrik (2005), p. 375.

119 Hayek (1976); North (1990); Roland (2000); and Mukand \& Rodrik (2005).

120 Rodrik (2008).

121 Qian (2000).

122 Qian \& Xu (1993), p. 141.

123 The rural township and village sector grew at an average of 22 percent per year between 1980 and 1995 (Jefferson \& Singh 1999).

124 Nee (1992). For an extensive account of the institutional framework of the TVEs, see Whiting (1996).
} 
given unreliable enforcement of formal rules. ${ }^{125}$ Chinese enterprises have their own characteristics and may require a different set of laws and institutions governing their establishment and organisation. China, like other East Asian countries, relies heavily on trust and informal human relationships, known as guanxi, to enforce business agreements. ${ }^{126}$ These informal institutions supplement the formal legal system, and are at least as important to economic growth. ${ }^{127}$ Local, informal institutions are "the fundamental explanation of such institutions' credibility and successful functioning." 128 China's institutional innovation has led some scholars to go as far to say that "China is contributing to the generation of new capitalist institutions domestically and globally" and that these new structures are "beginning to constitute a new form of capitalism."129

\section{Institutional change and reform}

China serves as a useful laboratory for the study of transition processes and institutional change. Economic theory has often driven the prescriptions for reform and change, but looking back at reform can also shed new light on economic theory. The central issue for reform is the creation of an institutional framework that provides the necessary incentives for a more efficient organisation of the economy. Reform of institutions seeks to "entrench an overarching framework that will enhance the working of the market mechanism, put the finances of the state on a sound footing that is consistent with economic efficiency and growth, and promote indigenous technological innovation."130 Efficient institutions should "provide clear, widely known, coherent, predictable, credible, and properly and evenly enforced rules."131

Institutional reforms arguably constitute the most difficult challenge for transition economies and developing economies. Reforms to embed institutions that provide the underpinnings of a market economy take a long time to implement and their benefits may take even longer to appear. For instance, a transparent and predictable legal system requires "substantial accumulation of very specialized

\footnotetext{
125 Burki \& Perry (1998), p. 141.

126 McMillan \& Naughton (1996); Hayami (1998); Fan \& Scott (2003); Hu, B. (2007).

$127 \mathrm{Hu}, \mathrm{B}$. (2007) provides a particularly compelling account of the importance of informal institutions to rural development in China. See also Huang, P. (2011) on the overall importance of informal economic practices to economic development in China.

128 Ho (2005), p. 18.

129 McNally (2008), p. 11.

130 Gang \& Woo (2009), p. 355.

131 Burki \& Perry (1998), p. 25.
} 
human capital, and the process of accumulating this specialized human capital involves learning by doing, which is time-consuming by nature."132 These types of institutional reforms cannot be achieved by way of a big-bang. ${ }^{133}$ History matters and actual institutions at any moment "represent adaptation to past as well as present difficulties." ${ }^{134}$ Therefore, viewed from an institutional perspective, no matter whether a big-bang or evolutionary approach is adopted, the end result is that transition is a gradual process. ${ }^{135}$

There is no agreed typology of theories of institutional change. Institutional change can be a top-down, state-dominant process focusing on formal institutions, such as promulgation of laws and constitutional reform. But it can also be a bottom-up process, driven by the interplay of spontaneous forces and competitive interests. ${ }^{136}$ Economic institutionalism emphasises the demands of economic interests, sociopolitical institutionalism centres on social or political power, legitimacy-based approaches stress popular preferences, while historical institutionalism seeks explanations in the impact of prior events. ${ }^{137}$ The latter school of institutionalism, to which this thesis most relates, considers that human beings are both norm-abiding followers and self-interested rational actors. It also considers that history matters because actors learn from experience, expectations are moulded by the past, and events occur within a historical context which directly affects decisions. ${ }^{138}$

Institutions change by necessity in response to a changing environment, which diminishes the efficiency of existing institutions. ${ }^{139}$ However, inefficient institutions may prove impervious to change due to vested interests and collective action problems, such as free riding. ${ }^{140}$ Informal institutions can change through the design of formal rules or as societal values evolve, and as the external environment changes. ${ }^{141}$ Those institutions dependent on culture, including values, beliefs and norms, are likely to produce incremental change and are thus slow-moving

\footnotetext{
132 Fan \& Woo (2009), p. 356.

133 Ibid.

134 Arrow (1998).

135 World Bank (1996).

136 Kingston \& Caballero (2009); Huang, X. (2011).

137 Gilley (2008).

138 See Steinmo (2008) for an extensive discussion of historical institutionalism.

139 Roland (2004).

140 Olson (1971).

141 Helmke \& Levitsky (2004).
} 
institutions. ${ }^{142}$ Political institutions, on the other hand, are typically fast moving, while legal systems sit somewhere in between.143 Technology, as the accumulated stock of knowledge, evolves continuously and slowly, but is also subject to irregular bursts of change. ${ }^{144}$

As suggested in the earlier discussion on gradualism, the process of institutional change in China has been marked by a high degree of path dependence as "new institutions are built before the old ones have been destroyed."145 Elements of the reform have "inescapably been time dependent" due to the absence of a blueprint for reform. ${ }^{146} \mathrm{An}$ example of the gradual approach and path dependence to institutional building can be found in the legal protection of companies:

Legal documents confirm the painfully slow expansion of official protection. At the start of reform, private business operated in legal limbo. Some entrepreneurs disguised their firms as collectives...A succession of amendments to China's 1982 constitution slowly expanded recognition of the nonpublic economy, first as a "complement" to the state sector (1988) and then as an "important component" (1999) of the "socialist market economy"...The long march toward official recognition of private business came to an end only in 2007 when, following five years of fierce debate, China's legislature enacted a landmark Law on Property Rights which, for the first time, explicitly places privately held assets on an equal footing with state and collective property. ${ }^{147}$

Institutions are difficult to borrow from other jurisdictions as they are constrained by the historical development path of the borrower and by the unique cultural heritage. Accordingly, Chinese reformers have adopted a syncretic approach, borrowing and adopting from a wide range of experiences, in seeking to devise institutions compatible to the local context:

...special economic zones were modelled much on the experience of Taiwan and Singapore; stock exchanges emulated Hong Kong's rules and practice; initial enterprise reforms drew inspiration from the Hungarian and Yugoslavian experience; the new tax system employed German expertise; banking reform relied heavily on the experience of the US Federal Reserves; and housing reform drew on the Singaporean approach. Reformers adhered to a market orientation in virtually all their reforms and gradually and selectively adopted foreign ideas and institutions. The result was some success and many setbacks. Yet certain new ideas and institutions have been

\footnotetext{
142 Williamson (2000) refers to these very slow moving institutions as "level 1" institutions. This "social embeddedness level" changes over centuries or millennia.

143 Roland (2004).

144 Ibid.

145 Qian (2000).

146 Naughton (1996), p. 5.

147 Brandt \& Rawski (2008), p. 19.
} 
gradually adapted and organically assimilated into the conditions that are unique to China. ${ }^{148}$

The formation and evolution of institutions is a dynamic process, shaped and driven by cultural traditions, customs, history, conventions, norms and practices. A particular feature of Chinese institutions is the role played by China's large diaspora. During the initial opening up, Chinese reformers sent many groups to study the experience of the "little dragons," in particular Hong Kong and Singapore. The Chinese in these economies had experience with market institutions and had "adapted market institutions from the West and internalized them in a Chinese cultural environment." 149 The overseas Chinese communities thus provided mainland China with models of market-based institutions that had been adapted to a Chinese cultural environment. This process of institutional substitution has been described as "indirect path dependence." 150

In summary, analysis of Chinese institutions requires discussion of both formal and informal institutions. Chinese institutions have tended to change incrementally, rather than abruptly with various institutional innovations emerging from experimentation. This suggests that informal institutions play a particularly important role in China given their slow rate of change. Institutions have been adopted and borrowed in a syncretic manner, but adapted to the local context. The Chinese diaspora have played an important role, as the frontrunners to marketbased institutions. The so-called "China puzzle" ought not to be assumed as a multitude of institutional settings can be pareto-improving.

\footnotetext{
148 Zhang (2000), p. 51

149 Ibid., p. 77.

150 Ibid., p. 77.
} 


\section{Innovation theories and innovation zones}

\section{National innovation system framework}

The theory of the national innovation system provides a systematic approach to understanding innovative and economic performance. 151 The theory is founded on the idea that innovation by firms involves complex interactions between a firm and its environment. While cross-border linkages and information flows are increasing along with the internationalisation of R\&D, national borders still matter, as do the unique institutional settings at the national level. The notion and very concept of a national system still therefore holds much pertinence, notwithstanding the vast size and regional dimensions inherent in a country the size of China. ${ }^{152}$

Rather than depicting firms as atomistic actors, the theory posits that the institutional and organizational framework as well as the social and cultural context shape firm behaviour. This theory therefore fits neatly with the institutional analysis of this thesis. The basic conceptual underpinnings of this theoretical approach are that economic behaviour rests on institutional foundations, competitive advantage is path-dependent, and interactive learning generates technological knowledge. 153 The system perspective points to the importance of knowledge flows and efficient interactions among all actors of the innovation system, in particular among firms, universities, public research organisations and technology policy, for successful innovation. ${ }^{154}$ Informal institutions are thus particularly important given their role in facilitating interaction and knowledge.

National innovation systems can either be defined narrowly to include "organisations and institutions involved in searching and exploring-such as R\&D departments, technological institutes and universities"155 or more broadly. The latter conception includes "all parts and aspects of the economic structure and the

\footnotetext{
151 Seminal publications in this theory are Freeman (1987); Lundvall (1992); Nelson (1993); OECD (1997).

152 Various studies affirm the importance of domestic innovation. See, for instance, Patel \& Pavitt

(1991). The role of provincial and sub-provincial governments in innovation has become more important over the past decade (Springut et al. 2011)

153 Smith (2000).

154 The Oslo Manual provides the internationally accepted definition of innovation: "An innovation is the implementation of a new or significantly improved product (good or service), or process, a new marketing method, or a new organizational method in business practices, workplace organisation or external relations." (Tanaka et al. 2005: 46).

155 Lundvall (1992), p. 12.
} 
institutional set-up affecting learning as well as searching and exploring-the production system, the marketing system and the system of finance..."156 Under the broad conception, innovation policies include science and technology, industrial, financial, tax and fiscal policies. China's Ministry of Science and Technology (MOST) has leaned towards the broad definition, as it treats tax incentives, R\&D subsidies, and trade restrictions and promotion as "innovation policies." 157 The following discussion thus adopts the broad understanding of innovation policies, but focuses extensively on science and technology given their centrality to ZGC.

\section{Innovation zones-definition}

The success and resilience of Silicon Valley, 158 Route 128, Research Triangle Park, Cambridge Science Park and the Emilia-Romagna clusters has led governments around the world, including that of China, to attempt to emulate their success. High-tech districts and science parks are increasingly being set up to facilitate technology transfer and regional development as they are often seen as leading to fast growing, geographically clustered firms within industries. ${ }^{159}$ These spatial areas, designed to generate innovation, are rooted in strong inter-firm networks as well as extensive linkages between research and industry. From a theoretical point of view innovation zones and technology parks are particularly interesting as they straddle theories of agglomeration, competitiveness and innovation.

Despite their popularity, ${ }^{160}$ no generally accepted definition of innovation zones or science parks exists. ${ }^{161}$ Science parks can encompass almost anything from distinct organisations to amorphous regions. Multiple terms exist for essentially the same phenomenon: research parks, technology parks, science parks, science-based industrial parks, technopoles or innovation milieux. ${ }^{162}$ To add further complication, it is often difficult to disentangle science parks from technology clusters and new

\footnotetext{
156 Ibid.

157 Liu et al. (2011).

158 Silicon Valley is home to the first science park to be established: Stanford Research Park. Founded in 1951, the park later became the cornerstone of Silicon Valley. See Saxenian (1996) for discussion of Silicon Valley and Route 128.

159 Tan (2006).

160 As at December 2012, IASP counted almost 400 members (each member is a science park) in 70 countries.

161 Amirahmadi \& Saff (1993); Storey \& Tether (1998); and Phan et al. (2005) provide useful overviews of the definitional and conceptual problems.

162 Some authors draw fine distinctions. For instance, Stankiewicz (1998) regards parks as more restricted that technopoli in spatial and institutional terms. However, there is no consistent categorisation. Link and Scott (2007) note that "research park" is more prevalent in the United States, "science park" is more common in Europe and "technology park" is more widespread in Asia.
} 
industry zones. ${ }^{163}$ For instance, Taiwan's three core science parks each have their own satellite industrial clusters. The name changes of ZGC through its history are symptomatic of the looseness of the concept and of the overlaps between science parks and industry zones. For ease of reference, this section refers to the term "innovation zones" as it is sufficiently broad to encompass science parks, clustering and high-tech industrial zones.

Innovation zones focus on business acceleration through knowledge agglomeration and resource sharing. According to the International Association of Science Parks and Areas of Innovation (IASP), "areas of innovation," of which science parks are a subset, fulfill the following functions:

- Stimulate and manage the flow of knowledge and technology between universities and companies

- Facilitate the communication between companies, entrepreneurs and technicians

- Provide environments that enhance a culture of innovation, creativity and quality

- Focus on companies and research institutions as well as on people: the entrepreneurs and knowledge workers

- Facilitate the creation of new businesses via incubation and spin-off mechanisms and accelerate the growth of small- and medium-sized enterprises (SMEs). ${ }^{164}$

At their core, science parks are places where research ideas and scientific achievements are developed into products for the market. 165 They provide an institutional framework to facilitate this process. They are not simply industrial zones for property development in which any firm may do business, but are targeted at firms with high levels of technological sophistication. Science parks seek to cluster science and technology organisations into geographically distinct zones. Their raison d'être is thus to improve industry-research linkages.

163 Park \& Markusen (1994); Zhou (2004). Storper and Harrison (1991) break industrial districts into six types based on input-output organisation and governance.

164 IASP website (2012).

165 Stankiewicz (1998). 
Industry-science linkages take many forms: "casual contacts between academic scientists and engineers, spin-offs from public research, licensing and patenting by universities, contract research, mobility of researchers, public- private partnerships for research, co-operation in training and education, etc."166 Networks and clusters facilitate relationships between industry and research as they stimulate creativity and allow a two-way exchange between curiosity-driven research and market-led innovation to the benefit of both. Accordingly, around 80 percent of parks are linked to a research institute and more than 90 percent house business incubators. ${ }^{167}$

The size, organisation and ownership of innovation zones varies significantly. Some are no more than several acres in central business districts, while others cover vast swathes of land. The largest in the United States is the Research Triangle Park at around thirty square kilometres, but ZGC dwarfs this by a factor of eight and the Zhangjiang Park in Pudong covers 500 square kilometres. ${ }^{168}$ The majority of zones are public initiatives, with around 15 percent private developments. ${ }^{169}$ Some are based mostly on the development of new, locally owned businesses that are linked to nearby research institutes or universities. ${ }^{170}$ These include Boston's Route 128, Silicon Valley, and to a certain extent ZGC. Others are based on R\&D branch plants of large multinational corporations. ${ }^{171}$ Some specialise in one or very few technology sectors, such as the South Korean zones, while almost half are "generalists." 172 Finally, some innovation zones developed spontaneously, such as the Route 128 area, while others, such as Stanford Research Park, were planned creations. ${ }^{173}$ In short, there is significant variation; no template exists from which to copy.

\section{Innovation zones-rationale}

There is no singular rationale for the establishment of innovation zones beyond the belief that they may be useful to promote economic development. Different

\footnotetext{
166 OECD (2008), p. 68.

167 IASP statistics (2012). Significant variation occurs across countries. For example, in the United Kingdom all science parks are associated with a university, but in Japan and in the United States this is not the case.

168 MacDonald \& Deng (2004).

169 IASP statistics (2012).

170 Three types of spin-off firms exist: (1) contract and consulting firms; (2) technology asset firms;

and (3) product-oriented firms. See Etzkowitz et al. (1998).

171 Goldstein \& Luger (1990).

172 IASP statistics (2012).

173 Amirahmadi \& Saff (1993).
} 
countries have developed their own conceptions of how science parks can promote economic growth. For instance, Japan sees technopoles and science parks as a way of promoting regional equality; Singapore and Taiwan view their high-tech zones as a way to promote national technology-led development; regions in the United States and the United Kingdom often see science parks as a tool in overcoming the collapse of traditional economic sectors and to compensate for a fall in traditional funding sources. ${ }^{174}$ They can therefore be seen as solving a whole host of divergent problems. Consequently, their establishment is often associated with heavy expectations.

The basic economic rationale for innovation zones and science parks stems from the idea that geographic concentration generates externalities through agglomeration. The standard theory of agglomeration, which dates back to Marshall (1890), states that firms cluster together to take advantage of potential positive externalities they generate for each other. A large number of studies have applied the Marshallian external economies to understand and explain industry concentration and agglomeration. ${ }^{175}$ These ideas have since been extended to the interactions and networks between industry and research.

Five forces drive the formation and growth of regional clustering ${ }^{176}$ of industries, according to agglomeration theories.

1. The concentration of several firms in a single location offers a pooled market for workers with industry-specific skills, lowering the probabilities of unemployment and of labour shortage. This encourages job mobility and consequently information transfer across organisational boundaries.

2. Informational spillovers enhance the production function of clustered firms. Knowledge spillovers arise from the specific characteristics of knowledge, namely that it is non-rivalrous, not universally accessible and partially excludable. ${ }^{177}$ They occur through the movement of workers across firms and through the sharing of ideas in both formal and informal settings.

\footnotetext{
174 Monck et al. (1988); Amirahmadi \& Saff (1993); Stankiewicz (1998); Koh et al. (2005); Tsai (2005). 175 See, for instance, Hoover (1948); Perroux (1955); Krugman (1991); Ellison \& Glaeser (1997); Glaeser (1998); Greenstone et al. (2010).

${ }^{176} \mathrm{An}$ industry cluster is a "geographically proximate group of interconnected companies and associated institutions in a particular field, linked by commonalities and complementarities." (Porter 1998: 199). Spatial agglomeration refers to a geographical concentration of firms whose mutual linkages may or may not exist (Malmberg 1996).

177 Nelson (1959); Arrow (1962).
} 
Geographic proximity speeds up the travel of ideas. ${ }^{178}$ Knowledge spillovers are limited by the absorptive capacity of firms. ${ }^{179}$

3. Localised industries can support the production of nontradeable specialised inputs through backwards and forward linkages. ${ }^{180}$ These linkages confer competitive advantage without requiring firms to sacrifice flexibility for economies of scale. ${ }^{181}$ Firms build formal and informal relationships to take advantage of complementarities.

4. Geographic concentration also allows for the realisation of scale economies, in knowledge creation and infrastructure provision.

5. Close proximity lowers transactions costs for firms. ${ }^{182}$

Research into the geography-economy nexus became more prominent following Porter's publication in 1990, The Competitive Advantage of Nations. Porter (1990) observed that the geographic concentration of firms in the same industry is "strikingly common around the world." 183 He argued that geographically clustered firms have played an important role in shaping the competitive landscape and technology transfer. The benefits of localisation arise less from agglomeration than from heightened local competition created by many firms competing next to each other. This in turn spurs innovation. Low barriers of entry in clusters produce high rates of new business formation, which enhance cluster advantages.

The notion of "embeddedness" has been emphasised as the key to the functioning of industrial agglomerations and science parks. ${ }^{184}$ Granovetter (1985) argued that most behaviour is closely embedded in networks of interpersonal relations and local networks. Informal ties, informal information exchange and trust that go beyond mere contract are critical to inter-firm linkages and collective learning which is an important source of competitiveness. ${ }^{185}$ Innovation, because of its inherently uncertain character, is especially vulnerable to a lack of trust. ${ }^{186}$ Trust can be built up over a period of time through repeated interactions which are

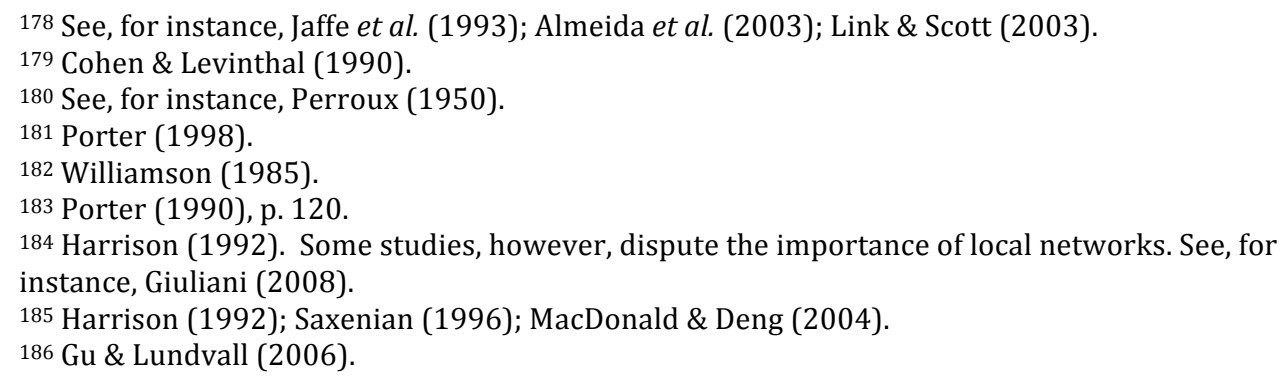


facilitated by geographical proximity. ${ }^{187}$ This social capital enables firms to cooperate with one another, sharing tools, information and even skilled personnel, yet also compete for market share. Various studies attest to the importance of informal links in science parks. 188

The role of government in the creation and development of science parks varies significantly. In the United States and the United Kingdom central governments have only been involved peripherally in park development. Central government cuts to research funding have, however, spurred universities to develop parks to increase revenues. ${ }^{189}$ In the United States, state and local governments have typically provided support through the provision of infrastructure, property tax reductions and favourable land use policies. ${ }^{190}$ This support has been regarded as crucial to the success of the parks. ${ }^{191}$

In contrast, the central governments of Japan, France and the Netherlands have played a major role in the creation and coordination of innovation zones. ${ }^{192}$ For instance, Japan's MITI launched the ambitious Technopolis Program in 1983 to steer high-tech industries toward particular regions. This approach was very topdown, but involved only limited financial assistance from Tokyo. ${ }^{193}$ The French government has set up two funds totalling 500 million euros for its pôles de compétitivité and since 2005 has financed 889 R\&D collaborative projects totalling 1.1 billion euros. ${ }^{194}$ In addition, the pôles benefit from subsidies and tax breaks. The French approach is a mix of top-down and bottom-up as local authorities submit pôle proposals, but ministry officials and reputed experts take decisions as to which proposals are funded. 195 Other East Asian governments, including Taiwan, Singapore and South Korea have invested significantly in innovation zones, providing supporting infrastructure and tax breaks as part of their active industrial policies. ${ }^{196}$ However, even in East Asia there is significant variation: the Taiwanese government has maintained a hands-off approach, leaving the private sector to

\footnotetext{
187 Park (1996); Saxenian (1996).

188 Westhead \& Storey (1995).

189 Webster \& Etzkowitz (1998).

190 Goldstein \& Luger (1990).

191 Amirahmadi \& Saff (1993).

192 Goldstein \& Luger (1990); Stankiewicz (1998).

193 Amirahmadi \& Saff (1993). See Araki (2000) for details on Japan's Technopolis programme.

194 DATAR \& DGCIS (2011).

195 Houel \& Daunis (2009); Ministère de l'Economie et des Finances (2011).

196 Amirahmadi \& Saff (1993); Koh et al. (2005); Tsai (2005); Yang et al. (2009).
} 
drive the development of Hsinchu; ${ }^{197}$ meanwhile Singapore's Biopolis is heavily state-led. ${ }^{198}$

\section{Innovation zones-effectiveness}

Innovation zones and science parks are seen as a mechanism for facilitating clusters, enhancing industry-science linkages and ultimately improving the competitiveness of a region or state through innovation. Yet despite their popularity and their theoretical attraction, the evidence on the effectiveness of parks suggests that they generally deliver less than anticipated. Science parks are not a quantitatively major phenomenon in the context of employment or the industrial structure as a whole. Their appeal rests in their symbolism as they bring together scientific research and industrial innovation, social relations and spatial elements. ${ }^{199}$

Science parks reflect an assumption that technological innovation stems from scientific research and that they can provide the catalytic incubator environment for the transformation of research results into production. ${ }^{200}$ This accords well with linear models of innovation in which there is a chain of successive interrelated activities: from basic research to applied and more developmental research activities, the development of new product and process ideas, the evolution and testing of prototypes, to commercial production. However, as the national innovation systems literature shows, innovation is the result of complex interactions with feedback loops. The innovation process is iterative with reverse flows from industry to academia, in which industrial innovation opens up new basic research questions. ${ }^{201}$ It is this knowledge flow from industry to universities that accounts for the success of Silicon Valley. ${ }^{202}$ Because science parks focus on pushing out research, some scholars contend that the very concept of science parks is flawed. ${ }^{203}$

Empirical studies on the effects of science parks on industry-science linkages generally show that parks do not significantly improve linkages. A study of links between higher education institutes and industry in the United Kingdom found that

\footnotetext{
197 Koh et al. (2005).

198 Ibid.

199 Massey \& Wield (1991).

200 Westhead \& Storey (1995).

201 See, for instance, Etzkowitz et al. (1998) on the "spiral model" of innovation.

202 MacDonald \& Deng (2004).

203 See, for instance, Massey \& Wield (1991); MacDonald \& Deng (2004).
} 
the links were less than anticipated, with the exception of Cambridge where the links were clearly present. ${ }^{204}$ Another study of 20 UK parks in 1986 showed that very few university start-ups conformed to the model of scientist turned entrepreneur. Links between research institutes in parks were low. 205 Other scholars have noted that links with academia are often peripheral rather than centre stage. 206 Researchers have also found a lack of synergies between laboratories and firms in the French and Japanese technopoles. ${ }^{207}$ On the positive side, when a university is present, parks can enhance the two-way transfer of knowledge between firms and between firms and universities. ${ }^{208}$

Studies on the effects on firms tend to find disappointing results. A study of science parks in the United Kingdom found that there were no statistically significant differences in R\&D intensiveness between on-park and off-park firms. ${ }^{209} \mathrm{~A}$ study of 16 Australian science parks revealed low levels of interaction among on-park firms and a low level of interest in research. ${ }^{210} \mathrm{~A}$ study of two Swedish science parks found that firms located on science parks had significantly higher survival rates than off-park firms, but that there were insignificant differences in firm growth. ${ }^{211}$ Research comparing high-tech companies on and off Shanghai science parks in 1999 found that there was little difference between the two sets of firms. The value of production and export income was not significantly different between the two groups. ${ }^{212}$ Another study of China's 53 high-tech parks found that there was no evidence of geographical external economies, but that parks had been successful in leveraging linkages with foreign companies. ${ }^{213}$ On the other hand, several scholars claim that science parks enhance the two-way knowledge flow between universities and industry and that therefore science parks have a role to play in the innovation system. ${ }^{214}$

The exceptions to these negative findings relate to Taiwan's Hsinchu Science-based Industrial Park (HSIP). Studies of HSIP have found statistically significant R\&D spillover effects and spatial spillover effects. Collaborative R\&D within and

\footnotetext{
204 Westhead \& Storey (1995).

205 Massey \& Wield (1991).

206 Webster \& Etzkowitz (1998).

207 Cooke (2001).

208 Link \& Scott (2011).

209 Westhead (1997).

210 Joseph (1989).

211 Ferguson \& Olofsson (2004).

212 MacDonald \& Deng (2004).

$213 \mathrm{Hu}$, A. (2007). This study used data from 1992 to 2000.

214 Link \& Scott (2007).
} 
between industries in Taiwan was found to play a more important role than the individual efforts of firms. In addition, scale economies were substantial in hightech clustering in HSIP. ${ }^{215}$ Another study found that HSIP firms invested more efficiently in R\&D than firms outside. These efficiency gains were attributed to the support of governmental policies for firms' R\&D efforts, the advantage of location, the effects of clustering and the social and economic bridge between HSIP and Silicon Valley formed through US-educated Taiwan engineers now working in HSIP. 216

The lack of tight linkages and overall effectiveness, beyond a few notable cases, has led some scholars to dismiss the notion of science parks altogether. Massey and Wield (1991) contend that public money from local taxes is used to subsidise profits made through property investment by financial institutions in the innovation zones. They argue that science parks produce social inequity, uneven development and hinder industrial regeneration. Other scholars note that science parks take at least a decade to become economically viable and that without government support they are not viable. ${ }^{217}$

Given the overall lack of success of science parks, it is clear that emulating the successes of Silicon Valley, Cambridge or Taiwan's Hsinchu Park is far from simple. The critical conditions for creating a successful science park still form an open question. What remains particularly elusive is how to develop the environment in which informal information exchange between firms themselves and between firms, research institutes and universities can occur. The social structures of sociability, trust and effective interactions among the actors in the innovation system fail to develop in "created" research parks. ${ }^{218}$ Not all spatial agglomerations of small firms necessarily make up a functioning innovation area. ${ }^{219} \mathrm{~A}$ functioning network of firms is required, underpinned by informal institutions, social capital220 and a regulatory environment favouring both collaboration and competition. ${ }^{221}$ The lack of inter-firm connectivity and network-supporting institutions, such as

\footnotetext{
215 Tsai (2005).

216 Yang et al. (2009).

217 Amirahmadi \& Saff (1993).

218 Malecki \& Oinas (1999).

${ }^{219}$ Harrison (1992).

220 In the case of Silicon Valley, social capital may be understood in terms of the dense and hypermobile personal networks of the professional and technical population, and the close links between powerful financial and industrial corporations and between innovation and commercialisation processes, rather than historically constructed social ties (Castilla et al. 2000). 221 Zhou (2004).
} 
mediating actors, rules of engagement, tech transfer mechanisms and informal interaction spaces, is a major impediment hampering the effectiveness of China's high-tech parks, including ZGC. 222

222 Walcott (2003). 


\section{Zhongguancun - development and evolution}

\section{The context-China's transitional system}

Two transitions are currently underway in China's national innovation system. First, the system is moving from the plan to the market, away from a centrally directed innovation structure to a more decentralised system. Second, Chinese leaders are attempting to shift the economy from a low-income developed country dependent on factor accumulation and low cost production to an economy capable of sustaining technological progress through technology adoption and innovation. ${ }^{223}$ Promotion of high-tech industry is arguably now the central economic development policy of the Chinese government.224

China has adopted a technological catch-up strategy with foreign direct investment and technology transfer and adoption at the centre, but once it reaches the technological frontier, innovation will be required to drive growth. ${ }^{225}$ Innovation depends on a competitive environment-the Schumpeterian "perennial gale of creative destruction" 226 - and a strong science and technology system closely connected with firms. However, building such a system is difficult, particularly in the absence of a formula and country-specific institutions. The experience of almost every developing economy shows that the transition to an innovative economy is exceedingly difficult. Only Japan, South Korea, Taiwan and Singapore stand out as unambiguous technology success stories.

Notwithstanding the challenge, China has bold aspirations and plans to bring about these two transitions. The latest catchphrase to emanate from Beijing is “independent/indigenous/endogenous innovation"227 (zizhu chuangxin 自主创新). The inaugural National Guidelines for Medium- and Long-term Plans for Science and Technology Development (2006-2020), issued by China's highest body the National People's Congress, aim to make China "an innovation-oriented country" by 2020 and foresee China becoming "the world's leading science power" by 2050.228

\footnotetext{
${ }^{223} \mathrm{Hu} \&$ Jefferson (2008).

224 Naughton (2007), p. 366.

225 For a discussion on a country's approach to the world technology frontier and innovation activities, see Acemoglu et al. (2006).

226 Schumpeter (1942/1987).

227 The translation of the Chinese term differs. Gu \& Lundvall (2006) contend that the term should simply be understood as "innovation."

228 Xinhua (2006a and 2006b).
} 
China's Five-Year Plans contain specific innovation, science and technology goals and targets that fall within the broader umbrella of the longer term guidelines.

This latest science and technology push comes on the back of increased investment in innovation ${ }^{229}$ and a series of reforms. The pre-reform science and technology system had been developed from the Soviet model. It was highly centralised with research capacities concentrated in government institutions. The system was effective in supporting basic research and centrally determined goals, but lacked the "complex incentive structure required for a broad-based system of commercial innovation that could effectively respond to the needs of the producer and consumer sectors operating outside the immediate realm of the government's science and technology priorities." 230 There was little interaction between institutions and linkages between research and production were poor. ${ }^{231}$ The sector relied on state patronage and was antithetical to the creation and protection of intellectual property rights. These features still plague the national innovation system today. Despite the more market-oriented system, it remains largely centrally controlled with most policies formulated and executed from the top. Interaction between users and producers of knowledge and innovation is limited. ${ }^{232}$

Reform of the science and technology system officially began in 1985 with the enactment of the Decision on the Reform of the Science and Technology Management System. The effects of the reform mirrored the "growing out of the plan" strategy observed in other sectors, i.e. a gradual diminishing importance of the state and increasing share of the private sector. This was driven by a gradual privatisation of research institutes, the introduction of competitive funding allocation mechanisms and cuts in government appropriations. ${ }^{233}$ The government reorganised its appropriations and established new programmes, including the Torch Programme, under which ZGC was created. Other key institutional changes to support

\footnotetext{
229 The appropriation for science and technology (both central and local government) increased from 35 billion RMB in 1996 to 169 billion in 2006. During the period of the $11^{\text {th }}$ Five-year plan (20062010), the central government's outlay for science and technology rose by 22 percent per annum (World Bank and Development Research Center of the State Council 2012).

${ }^{230} \mathrm{Hu} \&$ Jefferson (2008), p. 291.

231 This problem is not unique to China, but is the major stumbling block for innovation and science in centrally planned systems (Malecki 1991).

$232 \mathrm{Gu} \&$ Lundvall (2006); Hu \& Jefferson (2008); Liu et al. (2011); Springut et al. (2011); Benner et al. (2012).

233 Liu \& White (2001); Gao \& Tisdell (2004).
} 
innovation were the enactment of China's first patent law in 1983, laws on technology contracts in 1987 and a gradual implementation of copyright law.234

Reforms of the national innovation system as well as a more competitive business environment for domestic firms have led to an explosion in R\&D performed in China. The ratio of R\&D to GDP now stands at 1.7 , only slightly below that of Ireland, Canada, the United Kingdom and the Netherlands. ${ }^{235}$ Foreign firms are also establishing R\&D facilities in China to inter alia gain access to the Chinese market and reduce costs and the length of the R\&D cycle. ${ }^{236} \mathrm{R} \& \mathrm{D}$ personnel numbers have risen from 781,000 in 1986 to more than 2.5 million in 2010, the largest science and technology workforce in the world. ${ }^{237}$ As R\&D expenditure has increased, scientific outputs, such as scientific reports and patents, have risen. ${ }^{238}$ However, when weighted by the number of researchers, the numbers of articles published and patent applications lag significantly behind advanced economies indicating a lack of efficiency. 239

The increased investment and outputs in R\&D has not necessarily translated into increased quality. China has only partially succeeded in moving from a labourintensive, low-technology production to high-technology manufacturing. Exports of advanced technology products have soared, ${ }^{240}$ but foreign-owned firms have accounted for more than 96 percent of these exports since 2002.241 Very few Chinese firms can be counted among the technological leaders in their subsectors and few are significant producers of intellectual property. ${ }^{242}$ China produces relatively few high impact articles in any field and triadic patents are few in

\footnotetext{
${ }^{234}$ Gao \& Tisdell (2004).

235 OECD (2011). The OECD average for 2010 is 2.3 .

${ }^{236}$ Chen et al. (2008). Well-known multinational corporations with research facilities in China include IBM, Intel, Microsoft, Nokia, Ericson, SAP, Samsung and Matsushita.

237 Gao \& Tisdell (2004); OECD (2012). Note, however, that the OECD database on R\&D personnel for the United States is incomplete.

238 The number of scientific reports has risen dramatically, up from 20,000 papers in 1998 to 112,000 by 2008 (Adams et al. 2009). Patents granted by the Chinese patent office have swelled from 138 in 1985, to 149,588 in 2003 and 740,626 in 2010 (Gao \& Tisdell 2004; Website of the State Intellectual Property Office of the PRC). Patents issued by the US Patent Office to the Chinese private sector have surged since 2001 as have patent citation rates (Hu \& Mathews 2008). Patent citations are a more powerful indicator of innovation than simple patent counts. See Griliches (1990) and Jaffe \& Trajtenberg (2002) for in-depth analysis of the usefulness of patents in understanding innovation and technical change. 239 OECD (2008).

240 High-technology exports increased almost ten-fold between 2000 and 2010 (World Bank 2012a). 241 Moran (2011).

242 Notable exceptions include Huawei and ZTE in the ICT industry, Suntech Power in solar technologies and Dalian Machine Tool Group in engineering (World Bank and Development Research Center of the State Council 2012).
} 
number. ${ }^{243}$ Finally, a synthetic index of innovation rankings show China ranked $42^{\text {nd }}$ in the world, well behind OECD nations and a number of developing countries, including the Russian Federation, Brazil and Mexico. ${ }^{244}$

\section{ZGC-Pre-reform era}

The area comprising ZGC has been designated an educational and scientific research area within Beijing since the 1950s. In a bid to create a concentration of top scientists and engineers in China, the Chinese government either moved or established research institutes and universities in this area over time. By 1965, a total of 55 universities and research institutes were located in Beijing, concentrated principally in the northwestern district, known as ZGC. ${ }^{245}$ However, despite the research capacities, connections with industry were weak with the result that commercialisation and product development were severely limited. Under the command economy, no fewer than 40 supervisory agencies of different sectors at the national and local levels authorised universities and research institutes.

\section{ZGC-Embryonic stages of the zone, 1980-1988}

Inspired by Silicon Valley, several Chinese Academy of Science (CAS) researchers acted as risk takers and devoted themselves to an early experiment in establishing non state-owned firms ${ }^{246}$ in the ZGC area. They created China's first technology transfer-based organisation, despite stiff opposition. ${ }^{247}$ Dissatisfied with their working environment, these early entrepreneurs resigned from their high-status positions and created independent innovative firms. The opposition to this entrepreneurialism only came to an end in 1983 when the central government intervened through a positive assessment of China's first non state-owned innovative firm. By the end of 1983 eleven firms were operating in ZGC and by 1984 the number had topped $40 .{ }^{248}$ China's first cluster of high-tech related activity was subsequently created in the period 1984-87 when a group of computer stores on a particular thoroughfare in ZGC earned that section the nickname of "Electronics Street." By May 1988, the population of newly created firms had

243 Simon \& Cao (2009); OECD (2011).

${ }^{244}$ Archibugi et al. (2009).

245 Walcott (2003).

246 Many of these newly created companies were labelled "state-owned, people-run companies"

(guoyou minying 国有民营) (Zhou 2004).

247 Wang \& Wang (1998).

248 Zhao (1998). 
increased to 400, including major conglomerates which grew from individual inventions.

This early stage of the development of Beijing's high-tech agglomeration can be regarded as a process of spin-off from state-run research institutes and universities. The state institutions in the ZGC area encouraged the establishment of commercial firms as the firms' profits provided much needed financial relief in the wake of reductions in state funding. ${ }^{249}$ The CAS invested 300,000 RMB as seed money for the establishment of Legend and became the owner of the company. The state sector was also the dominant user during this formative stage. Entrepreneurs' existing networks with universities, government ministries and large SOEs were particularly important when negotiating contracts. ${ }^{250}$ Public research institutes and universities acted as venture capitalists by providing seed capital, technological expertise and name recognition. ${ }^{251}$ In addition to the networks with the state sector, personalised small firm networks were particularly important in this formative stage, as they were in the early days of Silicon Valley. ${ }^{252}$ However, these networks were "exclusive academic networks involving little participation from other commercial agents, such as banks, business services, and management."253

Through its pioneering organisational forms, the embryonic stage of ZGC set a precedent for ZGC's role in experimentation of innovation-related policies. Risktakers from China's state-run research institutes set up China's first high-tech firms, despite opposition. This initial experimentation was legitimised by the central government when it granted R\&D institutes nation-wide the authority to register various joint ventures with partners and to set up new technology enterprises in 1985.254 The spin-off companies were heavily reliant on state organisations and personal networks were fundamental to the emergence of the small innovative firm. Other informal institutions, in particular inter-firm networks were important at this stage. These developments would not have been possible without the region's deep indigenous R\&D base. Seeing the potential for productivity and innovation, Chinese reformers turned to formalising the zone, thus beginning the next stage of the life of ZGC.

\footnotetext{
249 Wang \& Wang (1998); Zhao (1998).

250 Zhou (2004).

251 Venture capitalists not only provide money, but also help start-ups formulate business strategy, assemble management teams, incubate promising projects and even assist in daily operations (Cao 2004: 650).

252 Wang \& Wang (1998).

253 Zhou (2004), p. 1119.

$254 \mathrm{Gu}(1996)$.
} 
In 1986, the State Science and Technology Commission investigated high-tech parks in other countries with the aim of replicating them in China. The CAS suggested making full use of the technical and scientific expertise concentrated in the ZGC area to develop a high-tech region. ${ }^{255}$ At the same time the Beijing Government began research into the establishment of high-tech development zones in China. After two years of investigation, the conclusion from both streams of work was that such zones were necessary and feasible. ${ }^{256}$ This formed the basis for the State Council's decision on May 10, 1988 to approve the development of a high-tech area in ZGC, designating 100 square kilometres of land in Haidian District ${ }^{257}$ as an "experimental zone" (shiyan qu 试验区). The State Council thus tentatively endorsed the early 1980s trials pioneered by CAS scientists. ZGC became Beijing's first formal new industrial district built largely around information technology.

The purpose of the formal zone was to promote direct linkages between research, technology and industry, foster technological and economic development and support new-technology industry. In its 1988 provisional regulations ${ }^{258}$ for the experimental zone, the State Council set out 18 preferential policies for firms, including foreign multinationals, located in the zone. Four principles underpinned the regulations: self-financing, self-chosen partners, self-operation, selfresponsibility for profit and loss. ${ }^{259}$ Tax reductions and exemptions comprised the most significant monetary incentives for locating in the zone, including:

- A reduction in corporate income tax to $15 \%$ (from $30 \%$ ) for new hightechnology firms and to $10 \%$ for high-technology firms with exports accounting for more than $40 \%$ of the value of annual production (Article $5(1))$.

- Corporate income tax exemption for start-up new technology firms for a period of three years and, with approval of the Beijing Municipal

255 Cao (2001)

256 Zhao (1998), p. 57.

257 In 1991, the Haidian Zone extended northwest to the Shangdi information industry incubator zone. Subsequently, the four sub-districts of the ZGC were set up: Changping Zone (1992), the Fengtai Zone (1992), the Yizhuang Zone (1998) and the Electronics Zone (1998). Note that during this phase of ZGC, no part of the Beijing Economic Technological Development Area (the BDA), approved by the State Council in 1994, formed part of ZGC.

258 State Council Provisional Regulations [1988] Beizhengfa No. 49.

259 Zhao (1998), p. 62. 
Government, a reduction in corporate income tax by half in the subsequent three years (Article 5(2)).

- A five-year exemption from construction tax for new buildings used for operating businesses and for developing technologies through selffinancing mechanisms (Article 5(4))

- In return, the tax foregone was required to be invested in the "National Support Fund" (guojia fuzhi jijin 国家扶植基金) (Article 8).

In addition to these tax holidays, other benefits included exemptions from import licensing, concessions to import tariffs, simplified approval processes (Article 7) and preferential foreign exchange loans (Article 9). The regulations also gave more autonomy to firms, allowing them to set their own prices and recruit their own university graduates and international experts (Articles 13 and 14). Importantly, the state did not bear any responsibility for their failure as ZGC firms became responsible for profit and loss (Article 10). They operated on the principle of selfreliance. Finally, China's first intranet connections were established in the ZGC area to facilitate information exchange among companies and research institutes. ${ }^{260}$

The regulations also allowed for ZGC firms to establish investment companies for joint ventures with international firms (Article 9), engage in trade, and, subject to approval from the relevant national ministries, set up branches offshore (Article 10). In return for this preferential treatment, the local government would receive a 20 percent share of the foreign exchange earnings after the third year. Following these loosening of restrictions, ZGC firms began entering into joint ventures with foreign companies with 1035 approved by the end of $1994 .{ }^{261}$ Sitong Corporation entered into a joint venture with Japan's National Electronics and the American Compay Corporation. The three largest Chinese computer related companies entered into partnerships with major global players: STRONG High Technology Development Group, an SOE, affiliated with Japan's National Electronics and Compaq; Legend Group (later Lenovo) became affiliated with Intel and Founders Group and set up its own company in Japan. In addition, former SOEs in electronics

260 Walcott (2003).

261 Wang \& Wang (1998). 
converted in the 1990s to private companies became partners with major foreign companies such as Siemens, Nokia, Motorola, Panasonic, Altel and LG. 262

Lured by the preferential policies, the number of firms in ZGC rose significantly over the period. By 1998, slightly over 6,000 high-tech companies operated within Beijing's experimental zone, compared to over 4,000 high-tech firms outside the zone. Collectively-owned firms rose from around 300 in 1988 to 1,500 in 1993 before declining sharply.263 Meanwhile shareholding firms rose quickly from the mid-1990s. These included China's three largest Chinese companies which began to produce and sell their own products. As was the case during the pre-1988 "embryonic" phase, ZGC's research institutes continued their pivotal role. By 1999, revenue from firms affiliated to Peking and Tsinghua Universities alone amounted to 12 billion RMB. 264

Officially titled "Beijing Experimental Zone for the Development of New Technology Industries," ZGC became China's first national-level Science and Technology Industrial Park (keji gongye yuan 科技工业园). ZGC's initial successes lay in "practices giving birth to privately run technology firms and transforming scientific achievements." 265 It was the first park "to establish market economic institutions adapted to socialism and the needs of high-tech industries, to align management conventions to international practice...to improve service institutions and intermediaries such as the trading of industry property rights...and to form support services suitable for high-tech industries." 266 ZGC thus served as a pioneering model for subsequent national high-tech development zones.

In March 1991, the State Council established a further 26 zones as national-level parks by way of a notice (tongzhi 通知) and released regulations to govern the high-tech zones. ${ }^{267}$ In November the following year the State Council approved 25 parks and in 1997 set up Shaanxi's Yangling Agriculture Development Zone. ${ }^{268}$ The local names vary by designation, but the 53 are considered a group with similar characteristics in official state documents.

\footnotetext{
262 Walcott (2003).

263 Zhou (2004).

264 High-tech firms accounted for more than 80 percent of this figure (Chen \& Kenney 2006).

265 Zhao (1998), p. 44. This and other translations from Chinese language source materials are those

of the author.

266 Ibid., p. 45 (author's translation).

267 State Council Notice [1991] Guofa No. 12.

$268 \mathrm{Gu}$ Yue.
} 
The set of national science parks was launched as part of the Torch Program to encourage the establishment of indigenous high-tech companies. The primary goal of the programme was to bridge the previously isolated domains of academia and business. The rationale was also grounded in a recognition of "the lack of institutions that would support new- and high-technology firm formation and other mechanisms of technological diffusion". ${ }^{269}$ As part of the scheme's institutional framework, the government encouraged universities and research institutes to create spin-off companies and technology-based business incubators. ${ }^{270}$ In setting up the programme, Chinese reformers sought to use Western models of geographically configured cluster development. ${ }^{271}$

The initial pulling power of ZGC's preferential policies became diluted as the national regulations for the science parks contained similar provisions to those already applying to ZGC. However, ZGC continued to be governed separately by the 1988 provisional regulations with the exception of investment in fixed assets and foreign exchange for which the wider regulations applied. ${ }^{272}$ While similar preferences were applied to the other science parks, the preference accorded to ZGC firms was greater. For instance, the eligibility criteria for benefiting from the 10 percent corporate income tax rate were looser for ZGC firms. ${ }^{273}$ Start-up firms benefited from tax breaks for three years in ZGC, but only two years elsewhere. Nor did new firms in other science parks benefit from tax breaks in years four to six. ${ }^{274}$

In effect, Chinese reformers thus continued to single out ZGC in its treatment. The State Council did not decide the area or general scope of the other parks, instead empowering the National Science Committee to take decisions. In contrast, the State Council determined the overall scope and area of ZGC, but left the "detailed scope" (juti fanwei 具体范围) such as the list of new technologies to the Beijing Government in accordance with the National Science and Technology Committee. The Beijing municipal government subsequently released “measures" (banfa 办法)

\footnotetext{
${ }^{269} \mathrm{Hu}$, A. (2007).

270 The Torch Programme specified criteria for the licensing of spin-off companies, established tax incentives and other preferential policies, and recognised intellectual property in evaluating proposed spin-off companies (Gu 1996). Incubators provide external sources of R\&D and other essential business services, including physical facilities and sometimes equipment.

271 Walcott (2003).

272 State Council Notice [1991] Guofa No. 12, Point 5.

273 ZGC firms with export values exceeding 40 percent of their value of annual production could benefit from an income tax rate of 10 percent. This contrasted with a much higher 70 percent threshold for firms in the other parks.

${ }^{274}$ Firms in the other science parks with revenue less than 300,000 RMB were not required to pay income tax. This was a new provision not extended to ZGC.
} 
specifying the scope of new technology and products and further details on the implementation of the regulations. ${ }^{275}$ These later formed the basis for MOST's criteria on the constitution of high-tech industries. ${ }^{276}$ The Management Commission of ZGC handles affairs such as licensing, taxation, international trade, finance and investment, employment, and intellectual property for new-tech firms. It also determines which firms qualify for State Scientific and Technological Loans. ${ }^{277}$

The most important institutional innovation to have emerged from the experimental zone related to ownership reform. Legend, one of the original ZGC spin-off companies from CAS, began distributing profits as dividends among employees in 1994 following approval by CAS. Five years later Legend converted its dividend distribution rights into stock options and implemented an employee stock-option scheme. The company's conversion to a corporation made the managerial team clearly responsible for the success of the company. ${ }^{278}$ Stone, another of ZGC's pioneering firms solved its ownership problem, i.e. unclear ownership rights, by developing a management buy-out scheme in 1999. It therefore served as an example for the separation of ownership rights from management rights. ${ }^{279}$ These precedents opened the way for a gradual acceleration of restructuring, especially in small-scale industry. 280 Another first for ZGC during this period was the first establishment of Customs facilities inside a high-tech zone in December 1995.281

\section{ZGC-Science and Technology Park, 1999-2009}

After its 11-year stint as an "experimental zone," ZGC became a "science and technology park" in 1999. The ZGC Science and Technology Park was proclaimed to be of equal significance to the two other flagships of Chinese reform, namely the developments of the special economic zone in Shenzhen and the Pudong district in Shanghai..282 The specific objective was for ZGC to become China's Silicon Valley as part of the government's attempt to move the Chinese economy further up the

\footnotetext{
275 Beijing Municipal Government Provisional Measures [1988]; Beijing Municipal Government Implementation Measures [1988] Beizhengfa No. 57.

276 Ministry of Science and Technology Notice [2000], Guokafa huozi No. 324.

277 Tan (2006).

278 Naughton (2007), p 323.

279 Cao (2001).

280 Naughton (2007), p. 324

281 China Customs Zhongguancun Website.

282 Zhou (2004).
} 
value chain from imitation and import-substitution to innovation and knowledge.283

On May 261999 the Beijing municipal government submitted a report to the State Council "requesting instructions" (qingshi 请示) on the speeding up of the construction of ZGC Science and Technology Park. The report contained details of the strategic direction, objectives, main areas of work and plans of ZGC. The State Council, on 5 July, responded to the Beijing government and MOST, agreeing to the principles outlined in the report. At the same time, the State Council set out general expectations:

For ZGC to act as a model example for the development of national new and high-tech industries, [the People's Government of Beijing Municipality and the Ministry of Science and Technology] must take note of and borrow from international experience in constructing science cities and establish ZGC Science and Technology Park with Chinese characteristics...The construction of ZGC Science and Technology Park must start out from the reality on the ground in ZGC and from the current conditions in China and carefully gather up the experiences and lessons from previous new and high-technology industry development zones. ZGC must display dominance and unique characteristics...There must be a favourable environment for bold reform and daring innovation which attracts and brings together outstanding business operators and science and technology professionals...ZGC must persist in opening up towards other zones in China and overseas and also promote its own development through competition. The park must closely follow in the tracks of global trends in the development of high-technology, be oriented towards the market and actively development new- and high-tech industries, including the software industry as well as biotechnology and pharmaceuticals....The work in establishing ZGC Science and Technology Park is the responsibility of the People's Government of Beijing Municipality which must strengthen its leadership, develop an overall plan and organize the park...284

Following these general guidelines from the State Council, the Beijing municipal government issued a set of regulations for "ZGC Science and Technology Park" in December 2001 which took effort on 1 January 2001. ${ }^{285}$ While the word experimental was taken out of the zone's formal title, the regulations clearly made reference to ZGC's ongoing role as an experimental area. Article Four stipulated:

Zhongguancun Science and Technology Park is an experimental zone for comprehensive reform to push ahead with the strategy of invigorating the country through science and education and to develop a market economy. It is to be a base for the demonstration of national scientific and technological innovations, the incubation and diffusion of science and technology

\footnotetext{
${ }^{283} \mathrm{Hu} \&$ Mathews (2008).

284 State Council Reply [1999] Guohan No. 45 (author's translation).

285 Beijing Municipal Government Regulations [2000] No. 25.
} 
achievements, and the nurturing of high-tech industrialisation as well as innovative talent.286

The regulations contained first-time articles on protecting enterprises' assets (Article 7) and allowed ZGC firms to pursue undefined commercial interests, so long as law did not forbid the actions. The Beijing government also encouraged the establishment of a venture capital market for SMEs through the allocation of funding and equity shares as well as low-interest loans (Articles 28-30). Finally, the regulations contained a number of articles to protect intellectual property rights (Articles 39-45).

Article 32 granted unprecedented flexibility with respect to Beijing's rigid household registration system. Companies in ZGC could hire college graduates regardless of their original household registration. This was a landmark change for a city that had practised some of the world's most restricted migration controls for forty years. ${ }^{287}$ In the first year alone, ZGC firms hired 5000 college graduates with non-Beijing household status. Without the law, all such graduates would have been forced to leave Beijing after graduation. 288

Besides the specific provisions outlined above, 1999 marked a significant change in the life of ZGC. Prior to 1999, ZGC had operated predominantly independently. However, in 1999, the ZGC Administrative Committee was raised to a level above that of the government of an urban district so that it was directly under the municipal government of Beijing, giving ZGC closer ties to the State Council. ${ }^{289}$ The promotion meant that ZGC firms "hold a far more influential position in the policymaking of the central state than previously possible."290 It also means that the government's role in the park is more "intrusive and omnipresent". ${ }^{291}$ While the ZGC Administrative Committee has "followed a strict policy of not interfering in companies that they serve," 292 it has adopted specific policies for different industries. ${ }^{293}$

\footnotetext{
286 (Author's translation).

287 Zhou (2004).

288 Beijing Qingnian Bao (2002).

289 Zhou (2004).

290 Ibid., p. 1122

291 Cao (2004), p. 649.

292 Wang (2011).

293 Sheng (2011).
} 
The increased eye of China's top leadership became more evident in 2005 when Wen Jiabao on an "inspection" (shicha 视察) of ZGC issued four requirements for the development of China's new and high-tech parks. ${ }^{294}$

(i) Their fundamental mission has always been to develop new and high-tech industries and build capacities in indigenous innovation. (ii) Their goal is to grow internationally competitive new and high-tech industries, deepen institutional reform and build the 'soft environment.' (iii) They must persist in travelling along the road of intensifying development in a reasonable manner. (iv) They must, on the basis of established policies, earnestly resolve the development difficulties and problems of national high-tech zones. ${ }^{295}$

Subsequent to the Premier's visit, the State Council published "The Minutes of the Meeting concerning Policy Measures to Support the Strengthening of Beijing Zhongguancun Science and Technology Park" in August 2005 which contained eight concrete policy measures. These included singling out specific items to promote: computer software and integrated circuits; new generation mobile communications; computers and the Internet; digital sound and video; photoelectric displays; and biopharmaceuticals. ${ }^{296}$

The State Council also decreed a heavy experimentation role for ZGC. For the first time, the State Council instructed ZGC to launch and carry out specific trials in venture capital, share transfer systems, property rights reforms for nationalised firms and spin-off companies, and government and defence procurement. The minutes stipulated that the General Office of the State Council would be responsible for oversight of the policy measures. The substance of these minutes was disseminated by the Beijing municipal government in December through guidance (yijian 意见) which contained further prescriptions and details, including on the specific products mentioned by the State Council and on the trials relating to property rights reform. ${ }^{297}$

The guidance from the Premier and the State Council quickly led to institutional innovation. The most ground-breaking experiment was ZGC's establishment of China's first over-the-counter stock trading pilot programme in 2006, known as the ZGC Stocks Quotation and Transfer system. ${ }^{298}$ The trading system provided an

\footnotetext{
294 Fan (2006).

295 Ibid. (author's translation).

296 Ibid.

297 Beijing Municipal Government Guidance [2005] Beizhengfa No. 22.

298 Yang (2006).
} 
electronic financing platform for non-listed start-up companies to raise funds, improving a company's financing ability. The system is referred to as "the third market" given its importance alongside the main board and the SME board. ${ }^{299}$ Firms that have traded on the "third board" were expected to gain easier access to the Shanghai or Shenzhen stock exchanges. The pilot scheme is a fundamental component of building a multi-level capital market in China.

However, institutional innovation was not only spurred by the 2005 State Council directives, but had been occurring spontaneously, as the history of ZGC might suggest. For instance, in 2001, a professional incubator company, Tsinghua Business Incubator Co/ (THBI) was set up in the park to help start-ups secure financial support, including venture capital from various companies, loans from banks, government funding and a RMB200 million investment fund for returning students from overseas. In addition, it provides concessions, including free incubation space for the first year, preferential rents for the first two years, introductions to professional consulting services, and assistance in networking with various institutions and organizations. In 2003, THBI incubated 70 start-ups and 27 graduated. 300

During this period, ZGC continued its expansion. In 1999, ZGC counted 68 higher education organisations and 213 research institutes universities. ${ }^{301}$ As of 2004, CAS had invested in and spun off more than 400 high-tech enterprises, eight of which had been publicly listed. By the end of 2005, ZGC boasted one third of China's national laboratories and accounted for one fifth of China's total R\&D expenditure. In 2006, further parks were added bringing the total to ten science parks. Zhongguancun thus became known as "one zone with ten parks" (yiqu shiyuan 一区 十园).302 Its predominant place in China's innovation system remained unparalleled. In 2007, ZGC accounted for $18 \%$ of Beijing's GDP, and accounted for one seventh of all income generated from China's 54 high-tech zones. ${ }^{303}$ The annual revenue of more than 800 ZGC firms exceeded 100 million RMB and 106 companies listed on the stock exchange, the highest of any national park. ${ }^{304}$

\footnotetext{
299 China Daily (2010).

300 Chen \& Kenney (2006).

301 Beijing Municipal Government Request for Instructions [1999]. Jingzhengwen No. 35.

302 ZGC website (2012).

303 Zhang, Y. (2008).

304 Ibid.
} 
ZGC-National Innovation Demonstration Zone, 2009-

The final stage of ZGC was marked by the State Council's approval to establish the "Zhongguancun National Innovation Demonstration Zone" in March 2009.305 As in 1999, the State Council set out general expectations and directives, stressing indigenous innovation, internationally competitive innovative firms and internationally recognised brands. The State Council required the Beijing municipal government and MOST "to display the advantages of innovative resources, accelerate reform and development..." 306 ZGC's role as an experimental zone was reaffirmed with the State Council requesting the Beijing municipal government to "launch a trial on stockholder rights" and "strengthen innovative trials to reform the financing of science and technology." 307

The State Council also broadened the remit of ZGC. It instructed ZGC to participate in national science and technology projects, placing emphasis on the following areas: electronics and information, biotechnology and pharmaceuticals, aviation and space flight, new materials, clean energy, modern agriculture, and energysaving and emission reduction. This represented a marked expansion of the activities in ZGC, whose main activities had hitherto been in the field of IT. The State Council instructed, inter alia, the Beijing municipal government and MOST to implement tax policy to support indigenous innovation and to use procurement policy to support the zone. It also established an inter-departmental coordination group to "support the establishment of the national demonstration zone, implement the stipulated policy measures and research and resolve the large development problems." 308

The State Council has continued its primordial role. It approved ZGC's development plan for 2011-2020. The plan set out new measures and pilot programmes and contained plans to grow ZGC revenues more than six-fold by $2020 .{ }^{309}$ Within the framework of the plan, special funds have been allocated to ZGC. For instance, the Beijing municipal government and four central government ministries, including the Ministry of Finance and the National Development and Reform Commission

\footnotetext{
305 State Council Reply [2009] Guohan No. 28.

306 Ibid. (author's translation).

307 Ibid. (author's translation).

308 Ibid. (author's translation).

309 Wang (2011).
} 
agreed to support the service industry in ZGC to the tune of 3 billion RMB over three years. 310

Subsequent to the State Council's directives, the Beijing municipal government issued a set of regulations for $\mathrm{ZGC}, 311$ which replaced those issued in December 2000. Compared to the previous regulations, the revised regulations focused extensively on the creation of innovation; the transfer of knowledge between higher education organisations, research institutes and firms; and the international competitiveness of innovative firms. They also reaffirmed ZGC's role in experimentation and comprehensive reform. For instance, Article Nine encouraged organisations and individuals carrying out activities in ZGC to "take the lead in experimenting" (xian xing xian shi 先行先试) with systems and institutions for indigenous innovation.

ZGC's role in experimentation appears to have stepped up a notch since the Demonstration Zone status. A more top-down approach to pilot schemes and trail programmes has emerged. Various government agencies have rolled out pilot programmes and trials specific to ZGC. For instance, the Ministry of Finance issued a two-year trial policy for ZGC allowing expenses relating to employee training and education to be tax deductible. ${ }^{312}$ The Ministry of Finance and the State Administration of Taxation issued pilot policies allowing high- and new-tech enterprises to take enhanced deductions for R\&D costs. ${ }^{313}$ The Ministry of Finance established a 3-5 year pilot fund of 1.5 billion RMB to support modern service development in ZGC. 314 The Bank of China designed and launched a SME financial service for scientific and technological firms. ${ }^{315}$

The success of the ZGC trial on over-the-counter trading platform led the State Council in August 2012 to expand the pilot program. ${ }^{316}$ The State Council agreed to extend the pilot zones to the Zhangjiang High-tech Industrial Development Zone in Shanghai, the Donghu High-tech Development Zone in Wuhan, ${ }^{317}$ and the Binhai High-tech Industrial Development Area. As part of the expansion of the trial, the China Securities Regulatory Commission set up a share transfer system for SMEs to

\footnotetext{
310 An (2011).

311 Beijing Municipal Government Regulations [2010] No. 12.

312 Ministry of Finance Notice [2010] Caishui No. 82.

313 Ministry of Finance Notice [2010] Caishui No. 81.

314 Ministry of Finance et al. Notice [2011] Caijianhan No. 32.

315 Bank of China (2011).

316 Wang (2012).

317 This zone became China's second national innovation demonstration in January 2010.
} 
bring other qualified industrial zones under the pilot programme and offer relevant services for unlisted companies in the pilot zones. ZGC thus continues to play a central role in experimenting with establishing an innovation-inducing institutional framework. 


\section{Discussion}

\section{Zhongguancun and Chinese institutions}

Throughout China's reform era ZGC has served as a hotbed for institutional innovation and reform in high-tech industries. It began with a bottom-up, spontaneous experiment in creating a technology-transferred firm, the forefather to Lenovo or Legend. This was a crucial stage of liberalisation in China, setting the stage for more comprehensive liberalisation in the late 1990s. ${ }^{318}$ While few spinoffs have been successful as Legend, ZGC is now host to many companies spun out of the high concentration of research institutes and universities. The park has also spawned several large conglomerates with upwards of a hundred companies listed on the exchange.

Testament to the innovative environment is that the majority of firms are small and medium-sized enterprises producing specialised products. ${ }^{319}$ Returning Chinese, are setting up many such firms and they are also generating knowledge spillovers for other local ZGC firms. ${ }^{320}$ Almost no ZGC firm is yet at the technological frontier, generating new-to-market innovations, but the number of innovative firms is steadily increasing. Further bottom-up trials in ownership reform and in corporate governance have served as models for other Chinese firms. ${ }^{321}$ These reforms laid the basis for the pilot in over-the-counter share trading which has recently been rolled out to other national parks.

These bottom-up experiments have been matched by top-down experiments at the behest of the State Council and the Beijing municipal government. The very establishment of an experimental zone in 1988 came with unprecedented preferential policies for high-tech industries, in particular tax breaks. The success of the trial led to ZGC serving as the model for the subsequent national-level hightech zones, set up from 1991. The State Council's approval of a science and technology park in ZGC in 1999 came with calls for bold reform and daring innovation. The regulations that followed from the Beijing municipal government strengthened commercial interests, granted unprecedented flexibility to the

\footnotetext{
318 Naughton (2007), p. 360.

319 Wang \& Wang (1998); Tan (2006).

320 Beijing Pindao (2004); Filatotchev et al. (2011).

321 Cao (2001); Naughton (2007), pp. 323-324.
} 
household registration system and supported the development of a venture capital market. The final stage in ZGC has seen further top-down trials, such as on R\&D tax credits by the Ministry of Finance.

The role of the State Council has been preeminent throughout the history of ZGC, but over time it appears to be playing a more important role. The State Council exercises its power through its directives, in the form of notices, minutes of meetings and in statements approving projects. Leaders also exercise their power through speeches, such as that given by Premier Wen Jiabao in 2005 in ZGC. Unlike regulations, these do not constitute law and are thus not formal institutions. This forces bureaucrats to study and discuss the speeches and writings of top leaders which lay out the desired course of public policy and explain what lower levels of officialdom should and should not do. ${ }^{322}$

The State Council's guidance for ZGC has become more prescriptive over time, now specifying particular sectors and products for ZGC. It has also instructed ZGC to carry out specific trials in recent years, whereas in the early years the experiments were bottom-up. The instructions given by the State Council are then reflected in formal regulations, which in the case of ZGC have been issued by the Beijing municipal government. The exception was in 1988 when the State Council issued the regulations on the experimental zone. As ZGC has turned into a national demonstration zone, there are concerns that ZGC may resemble the Maoist campaigns to "learn from Daqing and Dazhai." These cities were set up as "models" for Chinese industry and agriculture, but were singled out for political purposes as showcases. ${ }^{323}$ Because of its singular status as a national icon, criticism of ZGC is not tolerated by the park's administrators and in some cases company officers. ${ }^{324}$

The formal regulations governing ZGC have emphasised the protection of intellectual property since 2000. However, the lack of enforcement of intellectual property rights appears to be inhibiting innovation and collaboration. ZGC's software industry finds it difficult to survive owing to rampant piracy. ${ }^{325}$ For instance, pirated copies of the Chinese version of Windows have taken away the market of an indigenously developed Chinese language platform, a ground upon which many ZGC firms had first established their foothold. As the legal system

322 Brandt \& Rawski (2008), p. 16.

${ }^{323}$ Cao (2004).

324 Ibid.

325 Zhou (2004). 
protecting intellectual property has not been well established, the transfer of technological know-how often involves "endless lawsuits between state-owned institutions and their former employees working in the independent spin-offs." 326 That said, multinationals are continuing to undertake R\&D in ZGC as strong internal linkages among technologies enable them to appropriate value from $R \& D$, even in the face of inadequate external IP protection. ${ }^{327}$

More and more attention has been paid to the venture capital market and other financial market innovations in ZGC. However, a lack of clarity and transparency in governance structures increases risk for venture capitalists. ${ }^{328}$ Second, limited partnerships are taxed as either individuals or corporations, which discourages venture investment. Venture capitalists are forced to rely on "over-the-counter property-rights exchanges to conduct mergers and acquisitions, which in most cases would not maximize their return on investment." 329 The venture capital funds set aside by the government have been used to support risk-averse projects or are put into the stock market at the expense of technology-intensive start-ups. ${ }^{330}$ Nongovernment firms struggle to secure capital. Moreover, the Chinese government sponsors many foreign venture capitalists. 331

ZGC has undoubtedly led to institutional innovations in corporate governance, but murkiness still surrounds certain aspects of ownership. Reform is required around the distribution of ownership of spinoffs to the parties, the definition of employees within a firm, and the quantification of employee contributions. ${ }^{332}$ The ownership of spin-off firms is particularly unclear and can result in conflicts regarding the remittances the spin-offs should provide to their mother institutions. Founder Group company's first president was fired by Peking University because of his unwillingness to increase payments to levels that the university felt were "reasonable." 333 These problems may account for why university-affiliated spin-offs are less productive and export less than non-affiliated firms. ${ }^{334}$

\footnotetext{
326 Tan (2006), p. 840.

327 Zhao (2006).

328 Cao (2004).

329 Ibid., p. 663.

330 Ibid.

$331 \mathrm{Hu} \&$ Jefferson (2008).

332 Brandt \& Rawski (2008).

333 Chen \& Kenney (2006).

334 Ibid.
} 
Despite the calls for indigenous innovation, ZGC primarily serves as a distribution, processing and trading centre for foreign information technology companies, with limited indigenous innovation. ${ }^{335}$ The literature on innovation emphasises collaboration and the construction of bottom-up, informal networks for generating innovation. ${ }^{336}$ These personal networks, dependent on trust, emerge because of the difficulty of getting the right information at the right time. They also overcome the limitations of contractual arrangements that restrict collaboration. Research on collaboration in ZGC, however, suggests that informal personal networks are not a factor behind success in innovation projects in ZGC.337 Scholars have noted that local firms source production factors mainly from outside and the branches of multinational firms located in the park have much stronger links outside ZGC.338 Studies of other zones in China have also found a lack of interest in cooperation. ${ }^{339}$

One explanation for the general weakness of networks in ZGC lies in the regulatory framework governing ZGC. For instance, there is no history of contract law. If contracts are violated or firms are cheated, the victim must assume full costs to right the wrongs. ${ }^{440}$ This high risk associated with external transactions discourages flexible network arrangements. Another explanation for the tendency to shun collaboration lies in historic factors. In the planned economy, Chinese enterprises internalised everything from supply chains to providing welfare such as housing and daycare for their employees. Accordingly, "Chinese society has developed few mechanisms to facilitate transactions among enterprises as most market economies do." ${ }^{341}$ The corruption and irregularities in the use of legal systems undermines trust and consequently innovation and learning across organisational borders. ${ }^{342}$

The heavy role of the state in the spin-off companies may also be inhibiting the effect of networks in ZGC. Informal exchanges seem "not to be increasing any chance of cooperation for innovation, probably because many firms spun off from different state-owned tertiary institutions and have maintained strong relations with their parents who are under different government ministries or

\footnotetext{
335 Cao (2004); OECD (2008), p. 68.

336 See, for instance, Granovetter (1973); MacDonald \& Piekkari (2005).

337 Ramirez \& Dickenson (2010).

338 Wang \& Wang (1998).

339 See, for instance, Wang et al. (2010) for a study of ICT firms in Shenzhen.

340 Zhou (2004).

341 Ibid., p. 1128.

$342 \mathrm{Gu} \&$ Lundvall (2006).
} 
equivalents." ${ }^{343}$ These strong vertical ties with the state-owned parents work against the formation of networking among new innovative firms. While ZGC firms still rely heavily on university-trained employees, laboratories and faculty, ${ }^{344}$ most cooperation between scientists and businesspersons in ZGC has proven unsuccessful. 345 The disjuncture between industry and academia remains significant with research institutes acting as "by-standers rather than the leaders of innovation and technology transfer." 346

This is not to say that collaboration, informal networks and inter-firm linkages are absent in ZGC. Information exchange in ZGC occurs through periodicals and nonprofit organisations, such as the Beijing High-tech Firms Association. 347 Academic and alumni networks are also powerful networks. ${ }^{348}$ Collaboration between ZGC firms and multinationals is particularly strong, which is increasing the innovative capacities of local firms. ${ }^{349}$ Research has found that foreign R\&D, mostly from US and Japanese firms, has raised the domestic value added of local Chinese firms in ZGC. ${ }^{350}$ This effect is greater when the local ZGC firms have greater absorptive capacities. The R\&D activities of multinationals has also been found to enhance the clustering of domestic firms in ZGC by promoting the relocation of existing firms and stimulating entrepreneurship. ${ }^{351}$ Symbiotic partnerships form where local firms are able to dominate the distribution channels while the multinationals dominate the technology. ${ }^{352}$ MNCs thus help knit Chinese firms into global production networks of high-tech items.

Since the late 1980s, branch organisations of local ZGC firms have "flown" to other Chinese regions to take advantage of lower costs and to seek greater flexibility in their business operations. ZGC entrepreneurs frequently cite a Chinese proverb "The farther away from the emperor, the higher the sky (to fly)" (tian gao huangdi yuan 天高皇帝远). Moving out of Beijing, in particular to southern China, helps "the new-tech firms get rid of some rigidity and formality of the old system they

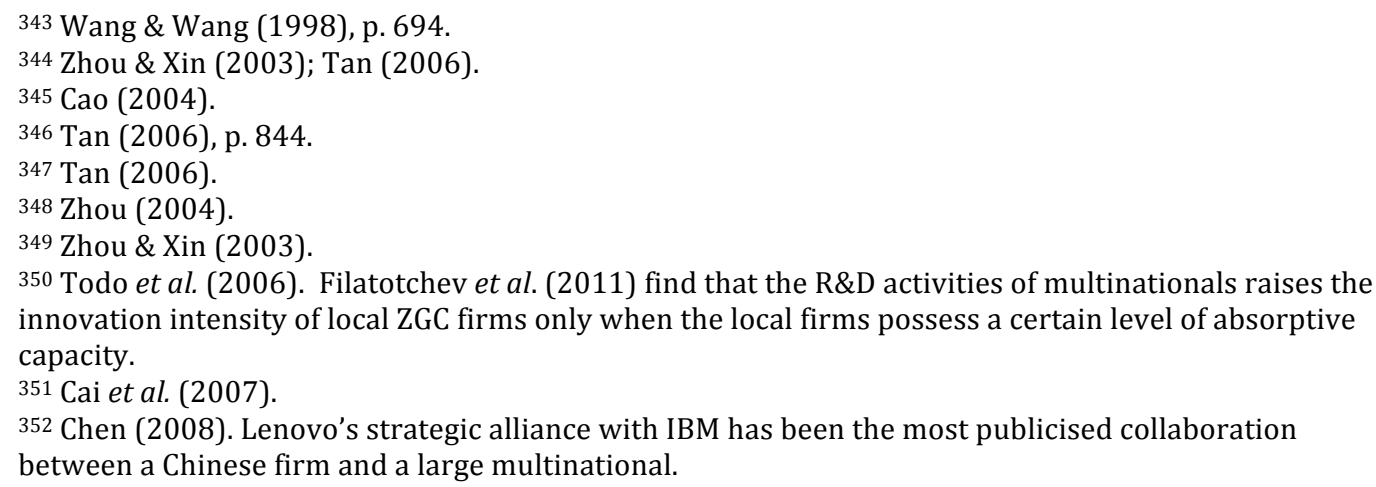


otherwise would have to deal with and to take advantage of informal, and in some cases illegal, channels to source their production factors nationally or even internationally." ${ }^{353}$ However, headquarters remain in ZGC to maintain guanxi. ${ }^{354}$ Establishing these connections takes a long time and entrepreneurs are therefore unwilling to leave this "relational capital" behind. Informal institutions thus play a role in ZGC, but overall the role of collaboration and informal networks is less than would be expected of a high-performing innovation area.

This flight to the south enables firms to partially escape the watchful eye of the state, but is also driven by lower costs in the south. As ZGC has grown, diseconomies of agglomeration have appeared. The cost of living, real estate prices and salaries have all risen. ${ }^{355}$ The high prices have become prohibitive for many start-up firms. Larger firms are investing in real estate pushing up prices, leaving less for small and medium-sized enterprises. ${ }^{356}$ Diseconomies of agglomeration appear to be increasing in ZGC as its popularity rises. This ought to be expected as the zone develops and matures. ${ }^{357}$

\section{Innovation zones: Chinese convergence?}

The discussion on innovation zones and science parks clearly showed that there is no clear definition or clear conceptual framework of innovation zones. However, common threads can be found in innovation zones, science parks and new industrial districts. These centre on agglomeration, clustering and industry-science linkages. Nevertheless, the variation around their scope, size and governance means that there is no international model around which ZGC or China's other high-tech zones could converge. Within China, there is also a definitional problem. Walcott (2003) notes the following:

China's high-tech industrial development zones encompass a wide variety of activities at each location. Some, as in Beijing, are centered on research institutions. Some in Shanghai are located around traditional manufacturing labour pools, or dictated in wholly new locations by government redistributive policy. Others reflect a geographical closeness to sites of overseas Chinese capital, such as Shenzhen, or military productive capacity, as in Xian. Local level STIP usually amount to little more than advertising for prestigious address, and principally hold manufacturing rather than R\&D activity. They are

\footnotetext{
353 Wang \& Wang (1998), p. 692.

354 Walcott (2003).

355 Tan (2006).

356 Ibid.

357 Ibid.
} 
far less innovative than industrious, and only major universities and institutes manage to produce any significant innovative breakthroughs. (pp. 56-57).

The role of government has been highly variable across the OECD and East Asia. However, there is a general trend across East Asia of a heavy state role in industrial and technology policies. ${ }^{358}$ Accordingly, the state's role in the creation of innovation zones has been greater than in OECD economies, with the possible exception of the French pôles de compétitivité programme. Scholars have noted the state's role has been critical in establishing science parks and in initiating new industrial districts in East Asia, particularly in South Korea. ${ }^{359}$ In this regard, the Chinese government's top-down approach to ZGC is similar to its neighbours.

At first glance, the sheer scale of ZGC and China's other high-tech zones appear to be a unique characteristic. Three-quarters of all high-tech activity in China takes place in its science parks and China's parks dwarf the largest in the United States. ${ }^{360}$ However, Taiwan's core science parks also account for the bulk of Taiwanese hightech exports. ${ }^{361}$ Nor are the policy measures, such as tax breaks, adopted by Chinese reformers unique to China. The OECD notes, "the use of tax incentives for $\mathrm{R} \& \mathrm{D}$ and tax breaks for incubators and university science parks are common in OECD countries." 362 The lack of inter-firm collaboration observed in ZGC and in other science parks has also been observed elsewhere in East Asia. ${ }^{363}$

What ostensibly sets ZGC apart is its role in experimentation and in political showcasing. Beijing has used ZGC to try out novel regulatory practices and to allow bottom-up experiments. This role has not been seen elsewhere in East Asia, neither for industrial districts, clusters, high-tech areas nor science parks. The latest move to use ZGC and Wuhan's West Lake Park to parade innovation before national and international eyes is also a point of divergence. Other states, including those in East Asia, have not created "national demonstration zones" for showcasing scientific and innovation achievements. This political leverage is not only limited to the national

\footnotetext{
358 Amsden (1989); Page (1994), pp. 253-260.

${ }^{359}$ Amsden (1989); Park \& Markusen (1995); Park (1996).

360 Ramirez \& Dickenson (2010), p. 96.

361 Republic of China Government Information Office (2011).

362 OECD (2008), p. 75.

363 See, for instance, Park (1996).
} 
demonstration zones. In many cases, high-tech parks in China are used "to showcase political correctness of the local leadership." 364

364 Cao (2004), p. 666. 


\section{Conclusion}

The development of a high-value, innovative economy presents Chinese reformers and policymakers alike with a formidable challenge. Few countries have succeeded as technology success stories. Yet China's unprecedented growth over the last three decades would suggest that China has the wherewithal to rise to the challenge, perhaps in the footsteps of its East Asian neighbours. Beijing is investing huge sums in science and technology and is continuing to foster a competitive environment conducive to Schumpeterian innovation. But this investment has not necessarily led to the anticipated improvements in quality. Few, if any, Chinese firms are at the technological frontier and inefficiencies remain in the research system.

China's reforms have been characterised by an overriding philosophy of gradual change and experimentation. This approach has allowed for institutional change to be pareto-improving by forming institutions that respond to the particular characteristics of the Chinese economy. This dynamic, interactive process has led to some unorthodox institutions and some claims of a China puzzle in the face of high growth. The institutional settings adopted by Chinese reformers have posed something of a challenge to those advocating a standard set of institutions that were successful for the West. The Chinese experience demonstrates that various institutional settings may be conducive to growth. These settings take account of local contexts and history. Institutional change is thus best managed through path dependent processes and a mix of evolutionary and more top-down approaches. The thesis thereby lends support to an historical institutionalist view of institutional change. Theories that ignore path dependency and evolutionary processes are not able to capture the complexities of institutional change.

The case of ZGC illustrates the importance of experimentation in China's transitional economy. Its very establishment was an experiment, and later served as a model for other high-tech national science and technology parks. Bottom-up experiments in ZGC created China's first high-tech firms, some of which have become large conglomerates. These pioneering firms have experimented with various corporate governance structures, serving as models for other Chinese firms. Stock trading systems, designed and trialled in ZGC, are now being rolled out beyond ZGC. In the last two years, top-down pilot schemes have gained momentum 
in the last two years with a number of government agencies using ZGC to experiment with innovation policies.

The institutional evolution of ZGC highlights the importance of bottom-up and topdown institutional change. Pioneering individuals took risks to establish new forms of organisation. Bottom-up institutional innovation continues in ZGC, but at the same time central and local government have later approved of these innovations through formal legal instruments. The State Council has been playing a more directive role over time, mostly through informal means, such as speeches and directives. These have tended to be followed up by formal regulations issued by the Beijing municipal government.

In spite of the institutional innovation that has occurred, ZGC has failed to address a number of institutional frameworks that underpin innovation. Chinese leaders have never been able to articulate coherent visions of ownership structure or of a restructured financial system. The intellectual property regime remains weak, which hinders knowledge creation, inter-firm collaboration and industry-research connections. The venture capital market is still embryonic, with non-state firms struggling to find capital. Spin-off firms have strong links with their parent SOEs and this vertical integration hinders networking among new innovative firms. The lack of formal institutions hinders the development of informal institutions, trust and social capital, which are essential to knowledge flows and networks. That said, guanxi do play an important role in company decisions to maintain their headquarters in ZGC despite the higher operating costs of locating in the zone.

The Chinese government has invested vast sums in ZGC and its other high-tech zones. However, based on evidence to date, the effectiveness of innovation parks is far from clear. They are at best a small part of a broader innovation framework. Science parks are one of many tools for improving industry-research connections. This confirms that China's approach to experimenting with institutions rather than simply copying western institutions and converging is the right approach. Following the model of Taiwan's Hsinchu may well prove fruitful, given the technological success across the Strait. Unlike studies of other parks, studies of Hsinchu show that the park does improve firm productivity.

There is a distinct lack of clarity around the concept of innovation areas and science and technology parks, which means that there is no particular institutional 
setting around which ZGC or Chinese parks could converge. However, it is clear that the experimental role being played by $\mathrm{ZGC}$ is unique. Recent research on innovation policy in the West suggests that experiments are required in determining the most suitable policy measures. ${ }^{365}$ China's history and established practices in experimentalism provide a strong platform for such testing. This augurs well for Chinese innovation policy and for the efforts of Chinese leaders to move the Chinese economy further up the value chain.

Successful innovation rests on decentralisation and freedoms to pursue new ideas and creative thought. Absence of political reform will hinder this process. Experimentation may generate institutional innovation, but in the absence of a thriving bottom-up process, major barriers to innovation in China will remain. Chinese leaders have placed high hopes on ZGC as a pioneer for transforming the Chinese economy, yet labelling ZGC a "national demonstration innovation zone" suggests that the zone will be used more for political purposes than for the generation of new ideas and knowledge with wide dissemination. Innovation in the West relied on a decentralised framework, empowering and incentivising individuals to find novel solutions to both old and new problems. ${ }^{366}$ It remains to be seen whether China will be successful in developing an alternative set of institutions capable of generating innovation. ZGC continues to be criticised for being no more than an export-processing zone, lacking in indigenous innovation. Further control from the centre may simply lock this in further. The study of institutional change in China's innovation system and the effectiveness of the institutions established is thus an area requiring further research. Understanding the drivers of innovation in different contexts, particularly in developing countries, is essential to improving living standards for ordinary citizens. Theories that are capable of explaining innovation and institutional change in multiple contexts need to be developed and these need to be tested alongside more established frameworks such as those of standard neoclassical economics which often drive reform and institutional change.

365 Chaminade et al. (2009).

366 Rosenberg \& Birdzell (1986). 


\section{Bibliography}

\section{Non-Chinese language}

Acemoglu, Daron, Simon Johnson and James A. Robinson (2005), "Institutions as a Fundamental Cause of Long-run Growth," in Philippe Aghion and Steven N. Durlauf (eds.) Handbook of Economic Growth, North-Holland: Elsevier B.V., pp. 385-472.

Acemoglu, Daron, Fabrizio Zilibotti and Philippe Aghion (2006), "Distance to Frontier, Selection, and Economic Growth," Journal of the European Economic Association 4(1), pp. 37-74.

Adams, Jonathan, Christopher King and Nan Ma (2009), "Global Research Report China: Research and collaboration in the new geography of science," Leeds: Thomson Reuters.

Allen, Franklin, Jun Qian and Meijun Qian (2005), "Law, finance, and economic growth in China," Journal of Financial economics, 77(1), pp. 57-116.

Almeida, Paul, Gina Dokko and Lori Rosenkopf (2003), "Startup Size and the Mechanisms of External Learning: Increasing opportunity and decreasing ability?," Research Policy 32(2), pp. 301-315.

Amirahmadi, Hooshang and Grant Saff (1993), "Science Parks: A critical assessment," Journal of Planning Literature 8(2), pp. 107-123.

Amsden, Alice H. (1989), Asia's Next Giant: South Korea and Late Industrialization, New York: Oxford University Press.

An, Lu (2011), “Beijing Receives Fund Injections to Develop Service Industry,” July 13 2011, Xinhua, available at the Chinese Government's Official Web Portal: http://english.gov.cn/2011-07/13/content_1905810.htm, accessed 23 August 2012.

Araki, Kousuke (2000), “Technological Innovation, National Urban Policy and Local Development: Policy implications of the concept of technopole and Japan's Technopolis Programme for developing countries," Working Paper No. 110, available at:

http://www.bartlett.ucl.ac.uk/dpu/publications/latest/publications/dpu-workingpapers/wp110.pdf, accessed 7 December 2012.

Archibugi, Daniele, Mario Denni and Andrea Filippetti (2009), "The Technological Capabilities of Nations: The state of the art of synthetic indicators," Technological Forecasting and Social Change 76(7), pp. 917-931.

Arrow, Kenneth J. (1998), "The Place of Institutions in the Economy: A theoretical perspective," in Yujiro Hayami and Masahiko Aoki (eds.) The Institutional Foundations of East Asian Economic Development: Proceedings of the IEA Conference held in Tokyo, Japan, New York: St Martin's Press, pp. 39-48. 
Arrow, Kenneth J. (1962), "Economic Welfare and the Allocation of Resources for Invention," in David M. Lamberton (ed.) Economics of Information and Knowledge, Harmondsworth: Penguin, pp. 141-159.

Bank of China (2011), "Maintaining Innovative Development and Serving SEMs (sic) for Win-Win of Bank and Enterprise," available at: http://www.bank-ofchina.com/en/bocinfo/bi1/201103/t20110309_1320115.html, accessed 21 August 2012.

Barzel, Yoram (1989), Economic Analysis of Property Rights, Cambridge and New York: Cambridge University Press.

Benner, Mats, Li Liu and Sylvia Schwaag Serger (2012), "Head in the Clouds and Feet on the Ground: Research priority setting in China," Science and Public Policy 39(2), pp. 258-270.

Brandt, Loren and Thomas G. Rawski (2008), “China's Great Economic Transformation," in Loren Brandt and Thomas G. Rawski (eds.) China's Great Economic Transformation, New York: Cambridge University Press, pp. 1-26.

Burki, Shahid Javed and Guillermo E. Perry (1998), Beyond the Washington Consensus: Institutions matter, Washington: The International Bank for Reconstruction and Development/THE WORLD BANK.

Cai, Hongbin, Yasuyuki Todo and Li-An Zhou (2007), "Do Multinational's R\&D Activities Stimulate Indigenous Entrepreneurship? Evidence from China's 'Silicon Valley,'” NBER Working Paper 13618.

Cao, Cong (2004), "Zhongguancun and China's High-Tech Parks in Transition: ‘Growing Pains' or 'Premature Senility?,'” Asian Survey 44(5), pp. 647-668.

Cao, Cong (2001), "Zhongguancun: China's Silicon Valley," The China Business Review, 28(3), pp. 38-41.

Castilla, Emilio J., Hokyu Hwang, Ellen Granovetter and Mark Granovetter (2000), "Social Networks in Silicon Valley," in Chong-Moon Lee, William Miller, Marguerite Hancock and Henry Rowen (eds.) The Silicon Valley Edge: A Habitat for Innovation and Entrepreneurship, Stanford: Stanford University Press, pp. 218-247.

Chaminade, Cristina, Bengt-Ake Lundvall, Jan Vang-Lauridsen and KJ Joseph (2009), "Towards a Systemic Experimentation-Based Approach," Paper presented at 7th Globelics Conference, Dakar 6-8 October 2009.

Chen, Kun and Martin Kenney (2007), "Universities/Research institutes and regional innovation system systems: the cases of Beijing and Shenzhen," World Development 35(6), pp. 1056-1074.

Chen, Ping (1993), "China's Challenge to Economic Orthodoxy: Asian reform as an evolutionary, self-organizing process," China Economic Review 4(2), pp. 137-142.

Chen, Yun-Cheng (2008), "Why Do Multinational Corporations Locate Their Advanced R\&D Centres in Beijing?," Journal of Development Studies 44(5), pp. 622644. 
Chen, Yun-Chung, Jan Vang and Cristina Chaminade (2008), "Regional Innovation Systems and the Global Location of Innovation Activities: Lessons from China," Working Paper 2008/18, Centre for Innovation, Research and Competence in the Learning Economy, Lund University, Sweden.

China Daily (2010), “OTC Market Firms Fair Well,” China Daily September 6, 2010, available at http://www.china.org.cn/business/201009/06/content_20871190.htm, accessed 22 August 2012.

Chow, Gregory C. (2002), China's Economic Transformation, Malden, Oxford and Carlton: Blackwell Publishing.

Chung, Jae Ho (2000), Central Control and Local Discretion in China: Leadership and implementation during post-Mao decollectivization, Oxford: Oxford University Press.

Clarke, Donald C. (1996), "The Creation of a Legal Structure for Market Institutions in China," John McMillan and Barry Naughton (eds.) Reforming Asian Socialism: The growth of market institutions, Ann Arbor: The University of Michigan Press, pp. 3959.

Coase, Ronald (1937), “The Nature of the Firm," Economica 4, pp. 386-405.

Cohen, Wesley M. and Daniel A. Levinthal (1990), "Absorptive-capacity: A new perspective on learning and innovation," Administrative Science Quarterly 35(1), pp. 128-152.

Cooke, Philip (2001), "From Technopoles to Regional Innovation Systems: The evolution of localised technology development policy," Canadian Journal of Regional Science 24(1), pp. 21-40.

DATAR and DGCIS (2011), "Lettre d'information des pôles de compétitivité," available at: www.competitivite.gouv.fr, accessed 11 December 2012.

Easterly, William and Ross Levine (2003), "Tropics, Germs, and Crops: How endowments influence economic development," Journal of Monetary Economics 50(1), pp. 3-39.

Easterly, William and Ross Levine (2001), "It's Not Factor Accumulation: Stylized facts and growth models," The World Bank Economic Review 15(2), pp. 177-219.

Ellison, Glenn and Edward L. Glaeser (1997), "Geographic Concentration in U.S. Manufacturing Industries: A dartboard approach," Journal of Political Economy 105(5), pp. 889-927.

Etzkowitz, Henry, Andrew Webster and Peter Healey (1998), "Introduction," in Henry Etzkowitz, Andrew Webster and Peter Healey (eds.) Capitalizing Knowledge, Albany: State University of New York Press, pp. 1-17.

Evans, Peter (2004), "Development as Institutional Change: The pitfalls of monocropping and the potentials of deliberation," Studies in Comparative International Development 38(4), pp. 30-52.

Fan, Cindy C. (1997), "Uneven Development and Beyond: Regional development theory in China," International Journal of Urban and Regional Research 21(4), pp. 620-639. 
Fan, Cindy C. (1995), "Of Belts and Ladders: State policy and uneven regional development in post-Mao China," Annals of the Association of American Geographers 85(3), pp. 421-449.

Fan, Cindy C. and Allen J. Scott (2003), "Industrial Agglomeration and Development: A survey of spatial economic issues in East Asia and a statistical analysis of Chinese regions," Economic Geography 79(3), pp. 295-319.

Fan, Gang (1994), "Incremental Changes and Dual-Track Transition: Understanding the case of China," Economic Policy 9(19) Supplement: Lessons for Reform, pp. 99122.

Feng, Yujun (2011), "Power, Rights, and Interests: A legal and economic analysis of urban housing demolition and relocation in China," in Xiaoming Huang (ed.) The Institutional Dynamics of China's Great Transformation, Oxon and New York: Routledge, pp. 78-97.

Ferguson, Richard and Christer Olofsson (2004), "Science Parks and the Development of NTBFs-Location, survival and growth," Journal of Technology Transfer 29(1), 5-17.

Filatotchev, Igor, Xiaohui Liu, Jiangyong Lu and Mike Wright (2011), "Knowledge Spillovers Through Human Mobility Across National Borders: Evidence from Zhongguancun Science Park in China," Research Policy 40(3), pp. 453-462.

Freeman, Chris (1987), Technology Policy and Economic Performance: Lessons from Japan, London: Pinter.

Gang, Fan and Wing Thye Woo (2009), "The Parallel Partial Progression (PPP) Approach to Institutional Transformation in Transition Economies: Optimize Economic Coherence, not Policy Sequence," Modern China 35(4), pp. 352-369.

Gao, Zhicun and Clem Tisdell (2004), "China's Reformed Science and Technology System: An overview and assessment," Prometheus: Critical Studies in Innovation 22(3), pp. 311-331.

Gilley, Bruce (2008), "Legitimacy and Institutional Change: The case of China," Comparative Political Studies 41(3), pp. 259-284.

Giuliani, Elisa (2008), "What Drives Innovative Output in Emerging Clusters? Evidence from the wine industry," SPRU Electronic Working Paper Series, Paper No. 169.

Glaeser, Edward L. (1998), “Are Cities Dying?,” The Journal of Economic Perspectives 12(2), pp. 139-160.

Glaeser, Edward L., Rafael La Porta, Florencio Lopez-de-Silanes and Andrei Shleifer (2004), “Do Institutions Cause Growth?," Journal of Economic Growth 9(3), pp. 271303.

Goldstein, Harvey A. and Michael I. Luger (1990), "Science/Technology Parks and Regional Development Theory," Economic Development Quarterly 4(1), pp. 64-78.

Granovetter, Mark (1985), "Economic Action and Social Structure: The problems of embeddedness," American Journal of Sociology 91(3), pp. 481-510. 
Granovetter, Mark S. (1973), "The Strength of Weak Ties," American Journal of Sociology 78(6), pp. 1360-1380.

Greenstone, Michael, Richard Hornbeck and Enrico Moretti (2010), "Identifying Agglomeration Spillovers: Evidence from winners and losers of large plant openings," Journal of Political Economy 118(3), pp. 536-598.

Griliches, Zvi (1990), "Patent Statistics as Economic Indicators: A survey," Journal of Economic Literature 28(4), pp. 1661-1707.

Gu, Shulin (1996), "The Emergence of New Technology Enterprises in China: A study of endogenous capability building via restructuring," Journal of Development Studies 32(4), pp. 475-505.

Gu, Shulin and Lundvall, Bengt-Åke (2006), "China's Innovation System and the Move towards Harmonious Growth and Endogenous Innovation," Innovation: Management, Policy, and Practice 8(1/2), pp. 1-26.

Haggard, Stephan (2004), "Institutions and Growth in East Asia," Studies in Comparative International Development 38(4), pp. 53-81.

Harrison, Bennett (1992), "Industrial Districts: Old Wine in New Bottles?," Regional Studies 26(5), pp. 469-483.

Hayami, Yujiro (1998), "Towards an East Asian Model of Economic Development," in Yujiro Hayami and Masahiko Aoki (eds.) The Institutional Foundations of East Asian Economic Development: Proceedings of the IEA Conference held in Tokyo, Japan, New York: St Martin's Press, pp. 3-35.

Hayek, Friedrich A. von (1976), The Constitution of Liberty, London: Routledge and Kegan Paul.

Heilmann, Sebastian (2009), "Maximum Tinkering under Uncertainty: Unorthodox Lessons from China," Modern China, 35(4), pp. 450-462.

Heilmann, Sebastian (2008a), "From Local Experiments to National Policy: The origins of China's distinctive policy process," The China Journal 59, pp. 1-30.

Heilmann, Sebastian (2008b), "Policy Experimentation in China's Economic Rise," Studies in Comparative International Development, 43(1), pp. 1-26.

Helmke, Gretchen and Steven Levitsky (2004), "Informal Institutions and Comparative Politics: A research agenda," Perspectives on Politics 2(4), pp. 725740 .

Heston, Alan and Terry Sicular (2008), "China and Development Economics" in Loren Brandt and Thomas G. Rawski (eds.) China's Great Economic Transformation, New York: Cambridge University Press, pp. 27-67.

Ho, Peter (2005), Institutions in Transition: Land ownership, property rights, and social conflict in China, New York: Oxford University Press.

Hoover, Edgar M. (1948), The Location of Economic Activity, New York: McGrawHill. 
Houel, Michel and Marc Daunis (2009), "Les pôles de compétitivité: bilan et perspectives d'une politique industrielle et d'aménagement du territoire," Information Report number 40, submitted to the Economic Commission of the French Senate.

Hsuing, James C. (2003), “The Aftermath of China's Accession to the World Trade Organisation," Independent Review 8(1), pp. 1086-1107.

Hu, Albert G.Z. (2007), "Technology Parks and Regional Economic Growth in China," Research Policy 36(1), pp. 76-87.

Hu, Albert G.Z. and Gary H. Jefferson (2008), "Science and Technology in China," in Loren Brandt and Thomas G. Rawski (eds.) China's Great Economic Transformation, New York: Cambridge University Press, pp. 287-336.

Hu, Biliang (2007), Informal Institutions and Rural Development in China, Oxon: Routledge.

Hu, Mei-Chih and John A. Mathews (2008), "China's national innovative capacity," Research Policy 37(9), pp. 1465-1479.

Huang, Philip, C.C. (2011), "The Theoretical and Practical Implications of China's Development Experience: The role of informal economic practices," Modern China 37(1), pp. 3-43.

Huang, Xiaoming (2011), "Introduction," in Xiaoming Huang (ed.) The Institutional Dynamics of China's Great Transformation, Oxon and New York: Routledge, pp. 124.

Huang, Xiaoming (2008), "Institutional competitiveness and institutional aging: the dynamism of East Asian Growth," Journal of the Asia Pacific Economy, 13(1), pp. 325 .

International Association of Science Parks and Areas of Innovation (IASP) website (2012), available at: http://www.iasp.ws/web/guest/the-role-of-stps-andinnovation-areas, accessed 24 December 2012.

International Association of Science Parks and Areas of Innovation (IASP) statistics (2012), available at: http://www.iasp.ws/web/guest/statistics, accessed 24 December 2012.

Jaffe, Adam B. and Manuel Trajtenberg (2002), Patents, Citations, and Innovations: A window on the knowledge economy, Cambridge and London: MIT Press.

Jaffe, Adam B., Manuel Trajtenberg and Rebecca Henderson (1993), “Geographic Localization of Knowledge Spillovers as Evidenced by Patent Citations," The Quarterly Journal of Economics 108(3), pp. 577-598.

Jefferson, Gary H. and Inderjit Singh (1999), “Overview” in Gary H. Jefferson and Inderjit Singh (eds.) Enterprise Reform in China: Ownership, transition, and performance, New York: Oxford University Press, pp. 1-22.

Jefferson, Gary H., Thomas G. Rawski and Yuxin Zheng (1999), "Innovation and Reform in China's Industrial Enterprises" in Gary H. Jefferson and Inderjit Singh 
(eds.) Enterprise Reform in China: Ownership, transition, and performance, New York: Oxford University Press, pp. 89-106.

Joseph, R.A. (1989), "Silicon Valley Myth and the Origins of Technology Parks in Australia," Science and Public Policy 16(6), pp. 353-365.

Kingston, Christopher and Gonzalo Caballero (2009), "Comparing Theories of Institutional Change," Journal of Institutional Economics 5(2), pp. 151-180.

Koh, Francis C.C., Winston T.H. Koh and Feichin Ted Tschang (2005), "An Analytical Framework for Science Parks and Technology Districts with an Application to Singapore," Journal of Business Venturing 20(2), pp. 217-239.

Krug, Barbara and Hans Hendrischke (2006), “China's Institutional Architecture: a New Institutional Economics and Organization Theory perspective on the links between local governance and local enterprises," 'Shifts in Governance' Conference, Hangzhou, July 2006.

Krugman, Paul (1991), "Returns and Economic Geography," Journal of Political Economy 99(3), pp. 483-499.

Li, Jingjie (1994), “The Characteristics of Chinese and Russian Economic Reform," Journal of Comparative Economics 18(3), pp. 309-313.

Li, Weisen (2011), “China's Road to Rechtsstaat: Rule of law, constitutional democracy and institutional change," in Xiaoming Huang (ed.) The Institutional Dynamics of China's Great Transformation, Oxon and New York: Routledge, pp. 98124.

Lin, Justin Y. (2012), Demystifying the Chinese Economy, New York: Cambridge University Press.

Link, Albert N. and John T. Scott (2011), "Research, Science, and Technology Parks: Vehicles for technology transfer," Department of Economics Working Paper Series, Working Paper 11-22, The University of North Carolina Greensboro.

Link, Albert N. and John T. Scott (2007), "The Economics of University Research Parks," Oxford Review of Economic Policy 23(4), pp. 661-674.

Link, Albert N. and John T. Scott (2003), "U.S. Science Parks: The diffusion of an innovation and its effects on the academic mission of universities," International Journal of Industrial Organization 21(9), pp. 1323-1356.

Liu, Feng-chao, Denis Fred Simon, Yu-tao Sun and Cong Cao (2011), “China's Innovation Policies: Evolution, institutional structure, and trajectory," Research Policy 40(7), pp. 917-931.

Liu, Xielin and Steven White (2001), "Comparing Innovation Systems: A framework and application to China's transitional context," Research Policy 30(7), pp. 10911114.

Lucas, Robert E. Jr. (1988), “On the Mechanics of Economic Development," Journal of Monetary Economics 22(1), pp. 3-42. 
Lundvall, Bengt-Åke (ed.) (1992), National systems of innovation: Towards a theory of innovation and interactive learning, London: Pinter.

MacDonald, Stuart and Yunfeng Deng (2004), "Science Parks in China: A cautionary exploration," International Journal of Technology Intelligence and Planning 1(1), pp. $1-14$.

Macdonald, Stuart and Rebecca Piekkari (2005), "Out of Control: Personal networks in European Collaboration," R\&D Management 35(4), pp. 441-453.

McMillan, John and Barry Naughton (1996), "Elements of Economic Transition," in John McMillan and Barry Naughton (eds.) Reforming Asian Socialism: The growth of market institutions, Ann Arbor: The University of Michigan Press, pp. 3-15.

McNally, Christopher A. (2008), "Reflections on capitalism and China's emergent political economy" in Christopher A. McNally (ed.) China's Emergent Political Economy, Oxon and New York: Routledge, pp. 17-35.

Malecki, Edward J. (1991), Technology and Economic Development: The dynamics of local, regional, and national change, Harlow: Longman Group.

Malecki, Edward J. and Päivi Oinas (1999), "Spatial Innovation Systems," in Edward, J. Malecki and Päivi Oinas (eds.) Making Connections: Technological learning and regional economic change, Aldershot: Ashgate Publishing Company, pp. 7-33.

Malmberg, Anders (1996), "Industrial Geography: Agglomeration and local milieu," Progress in Human Geography 20(3), pp. 392-403.

Marshall, Alfred (1890), Principles of Economics Volume 1, London: MacMillan.

Massey, D. and D. Wield (1991), "Science Parks: A concept in science, society, and 'space' (a realist tale)," Environment and Planning D: Society and Space 10(4), pp. 411-422.

Ministère de l'Economie et des Finances (2011), "Dossier documentaire - Les pôles de compétitivité," published 23 September 2011, available at:

http://www.economie.gouv.fr/cedef/dossier-documentaire-poles-competitivite, accessed 11 December 2012.

Monck, Charles, Dick Porter, Paul Quintas, David Storey and Pooran Wynarczyk (1998), Science Parks and the Growth of High Technology Firms, London: Croom Helm.

Moran, Theodore H. (2011), "Manufacturing Multinationals and the Transformation of the Chinese Economy: New measurements, new perspectives," Working Paper Series WP 11-11, Washington DC: Peterson Institute for International Economics.

Mosteller, Frederick (2006), Selected Papers of Frederick Mosteller, New York: Springer.

Mukand, Sharun and Dani Rodrik (2005), "In Search of the Holy Grail: Policy convergence, experimentation, and economic performance," The American Economic Review 95(1), pp. 374-383. 
Naughton, Barry (2007), The Chinese Economy: Transitions and Growth, Cambridge, MA: the MIT Press.

Naughton, Barry (1996), Growing Out of the Plan: Chinese economic reform, 19781993, Cambridge: Cambridge University Press.

Nee, Victor (1992), "Organizational Dynamics of Market Transition: Hybrid forms, property rights, and mixed economy in China," Administrative Science Quarterly 37(1), pp. 1-27.

Nee, Victor and Sijin Su (1996), "Institutions, Social Ties, and Commitment in China's Corporatist Transformation," in John McMillan and Barry Naughton (eds.) Reforming Asian Socialism: The growth of market institutions, Ann Arbor: The University of Michigan Press, pp. 111-134.

Nelson, Richard R. (ed.) (1993), National innovation systems: A comparative study, New York: Oxford University Press.

Nelson, Richard R. (1959), "The Simple Economics of Basic Scientific Research," Journal of Political Economy 67(3), pp. 297-306.

North, Douglass C. (2005), Understanding the Process of Economic Change, Princeton and Oxford: Princeton University Press.

North, Douglass C. (1990), Institutions, Institutional Change and Economic Performance, Cambridge and New York: Cambridge University Press.

North, Douglass C. and Robert Paul Thomas (1973), The Rise of the Western World, Cambridge: Cambridge University Press.

OECD (2012), Main Science and Technology Indicators, available online at: http://stats.oecd.org/Index.aspx?DataSetCode=PERS_OCCUP\#, accessed 18 December 2012.

OECD (2011), OECD Factbook 2011-2012: Economic, Environmental and Social Statistics, Paris: OECD.

OECD (2008), OECD Reviews of Innovation Policy, China, Paris: OECD.

OECD (1997), National Innovation Systems, Paris: OECD.

Olson, Mancur (1971), The Logic of Collective Action: Public goods and the theory of groups, New York: Schocken Books.

Page, John (1994), "The East Asian Miracle: Four Lessons for Development Policy," in Stanley Fischer and Julio J. Rotemberg (eds.) NBER Macroeconomics Annual 1994, Volume 9, MIT Press, pp. 219-282.

Park, Sam Ock (1996), "Networks and Embeddedness in the Dynamic Types of New Industrial Districts," Progress in Human Geography 20(4), pp. 476-493.

Park, Sam Ock and Ann R. Markusen (1995), "Generalizing New Industrial Districts: A theoretical agenda and an application from a non-Western economy,"

Environment and Planning A 27(1), pp. 81-104. 
Patel, Pari and Keith Pavitt (1991), "Large Firms in the Production of the World's Technology: An important case of 'non-globalisation'," Journal of International Business Studies 22(1), pp. 1-21.

Perroux, François (1955), "Note sur la notion de 'pôle de croissance'," Economie Appliquée Jan-June, pp. 307-20.

Perroux, François (1950), “Economic Space: Theory and Applications," Quarterly Journal of Economics 64(1), pp. 89-104.

Phan, Phillip H., Donald S. Siegel and Mike Wright (2005), "Science Parks and Incubators: Observations, synthesis and future research," Journal of Business Venturing 20(2), pp. 165-182.

Porter, Michael E. (1998), On Competition, Boston: Harvard Business School Press.

Porter, Michael E. (1990), The Competitive Advantage of Nations, New York: Free Press.

$\mathrm{Pu}, \mathrm{Bao}$, Renee Chiang and Adi Ignatius (trans. and eds.), (2009), Prisoner of the State: The secret journal of Premier Zhao Ziyang, foreword by Roderick MacFarquhar, New York: Simon \& Schuster.

Qian, Yingyi (2003), "How Reform Worked in China," in Dani Rodrik (ed.) In Search of Prosperity: Analytic Narratives on Economic Growth, Princeton: Princeton University Press, pp. 297-333.

Qian, Yingyi (2000), “The Process of China's Market Transition (1978-1998): The evolutionary, historical, and comparative perspectives," Journal of Institutional and Theoretical Economics, 156(1), pp.151-171.

Qian, Yingi and Joseph Stiglitz (1996), "Institutional Innovations and the Role of Local Government in Transition Economies: The case of Guangdong Province of China," in John McMillan and Barry Naughton (eds.) Reforming Asian Socialism: The growth of market institutions, Ann Arbor: The University of Michigan Press, pp. 175-193.

Qian, Yingyi and Chenggang Xi (1993), "Why China's Economic Reforms Differ: the M-form hierarchy and entry/expansion of the non-state sector," Economics of Transition 1(2), pp. 135-170.

Ramirez, Matias and Peter Dickenson (2010), "Gatekeepers, Knowledge Brokers and Inter-Firm Knowledge Transfer in Beijing's Zhongguancun Science Park," International Journal of Innovation Management 14(1), pp. 93-122.

Rawski, Thomas G. (1995), "Implications of China's Reform Experience," The China Quarterly 144 Special Issue: China's Transitional Economy, pp. 1150-1173.

Republic of China Government Information Office (2011), "The Republic of China at a Glance 2011," available at: http://www.roc-taiwan.org/glance/en/ch8.htm, accessed 31 December 2012.

Rodrik, Dani (2008), Second-best Institutions, National Bureau of Economic Research Working Paper 14050. 
Rodrik, Dani (1998), “TFPG Controversies, Institutitons and Economic Peformance in East Asia," in Yujiro Hayami and Masahiko Aoki (eds.) The Institutional Foundations of East Asian Economic Development: Proceedings of the IEA Conference held in Tokyo, Japan, New York: St Martin’s Press, pp. 79-101.

Rodrik, Dani, Arvind Subramanian and Francesco Trebbi (2002), "Institutions Rule: The primacy of institutions over geography and integration in economic development," National Bureau of Economic Research Working Paper 9305.

Roland, Gérard (2004), "Understanding Institutional Change: Fast-moving and slow-moving institutions," Studies in Comparative International Development 38(4), pp. 109-131.

Roland, Gérard (2000), Transition and Economics: Politics, markets, and firms, Cambridge, MA: MIT Press.

Romer, Paul M. (1986), "Increasing Returns and Long-Run Growth," Journal of Political Economy 94(5), pp. 1002-1037.

Rosenberg, Nathan and Birdzell, L.E. Jr. (1986), How the West Grew Rich: The economic transformation of the industrial world, New York: Basic Books.

Sachs, Jeffrey, D. (1993), Poland's Jump to the Market Economy: based on the Lionel Robbins Memorial Lectures delivered at the London School of Economics, January 1991, Cambridge, MA: MIT Press.

Sachs, Jeffrey, D. and Wing Thye Woo (1997), “Understanding China's Economic Performance," NBER Working Paper Series, Working Paper 5935, Cambridge, MA: National Bureau of Economic Research.

Sachs, Jeffrey, Wing Thye Woo and Xiaokai Yang (2000), "Economic Reforms and Constitutional Transition," Annals of Economics and Finance 1, pp. 423-479.

Saich, Tony (2000), "The Authoritarian State: China," in Joseph S. Nye and John D. Donahue (eds.) Governance in a Globalizing World, Washington, DC: Brookings Institution Press, pp. 208-228.

Saxenian, AnnaLee (1996), Regional Advantage: Culture and competition in Silicon Valley and Route 128, Cambridge, MA: Harvard University Press.

Schumpeter, Joseph (1942), Capitalism, Socialism and Democracy (sixth edition 1987), London: Unwin Paperbacks.

Sheng, Hong (2011), "Institution Formation, Imitation, and Borrowing: Zhongguancun as a case study on mechanisms of institutional change," in Xiaoming Huang (ed.) The Institutional Dynamics of China's Great Transformation, Oxon and New York: Routledge, pp. 36-54.

Simon, Denis F. and Cong Cao (2009), China's Emerging Technological Edge, Cambridge: Cambridge University Press.

Smith, Adam (1999), The Wealth of Nations, with an introduction by D.D. Raphael, London: David Campbell Publishers Ltd. (Original work published 1776). 
Smith, Keith (2000), "Innovation as a Systemic Phenomenon: Rethinking the role of policy," Enterprise and Innovation Management Studies, 1(1), pp. 73-102.

Springut, Micah, Stephen Schlaikjer and David Chen (2011), “China’s Program for Science and Technology Modernization: Implications for American Competitiveness," Prepared for the U.S.-China Economic and Security Review Commission, Arlington: CENTRA Technology, Inc.

Stankiewicz, Rikard (1998), "Science Parks and Innovation Centres," in Etzkowitz, Henry, Andrew Webster and Peter Healey (eds.) Capitalizing Knowledge, Albany: State University of New York Press, pp. 133-147.

State Intellectual Property Office of the P.R.C., webpages on patent statistics, available at:

http://english.sipo.gov.cn/statistics/gnwsqnb/2010/201101/t20110125_570600. html and http://english.sipo.gov.cn/statistics/200804/t20080416_380889.html, accessed 8 December 2012.

Steinmo, Sven (2008), "What is Historical Institutionalism?," in Donatella Della Porta and Michael Keating (eds.) Approaches in the Social Sciences, Cambridge: Cambridge University Press, pp. 150-178.

Storey, D.J. and B.S. Tether (1998), "Public Policy Measures to Support New Technology-based Firms in the European Union," Research Policy 26(9), pp. 10371057.

Storper, Michael and Bennett Harrison (1991), "Flexibility, Hierarchy and Regional Development: The changing structure of industrial production systems and their forms of governance in the 1990s," Research Policy 20(5), pp. 407-422.

Tan, Justin (2006), "Growth of Industry Clusters and Innovation: Lessons from Beijing Zhongguancun Science Park," Journal of Business Venturing 21(6), pp. 827850.

Tanaka, Nobuo, Michel Glaude and Fred Gault (2005), Oslo Manual: Guidelines for collecting and interpreting innovation date (third edition), Paris: OECD and Eurostat.

Tian, Qunjian (2004), "China Develops its West: motivation, strategy and prospect," Journal of Contemporary China 13(41), pp. 611-636.

Todo, Yasuyuki, Weiying Zhang and Li-An Zhou (2006), "Intra-Industry Knowledge Spillovers from Foreign Direct Investment in R\&D: Evidence from a Chinese Science Park," available at SSRN:

http://papers.ssrn.com/sol3/papers.cfm?abstract_id=938079, accessed 21 August 2012.

Tsai, Diana H.A. (2005), "Knowledge Spillovers and High-technology Clustering: Evidence from Taiwan's Hsinchu Science-based Industrial Park," Contemporary Economic Policy 23(1), 116-128.

UNESCO Institute for Statistics, Data Centre, available online at: http://stats.uis.unesco.org/unesco/TableViewer/document.aspx?ReportId=143\&I F_Language $=$ eng. 
Walcott, Susan M. (2003), Chinese Science and Technology Industrial Parks, Aldershot: Ashgate Publishing.

Walder, Andrew G. (1995), “China's Transitional Economy: Interpreting its significance," The China Quarterly 144 Special Issue: China's Transitional Economy, pp. 963-979.

Wang, Cassandra C., George C. S. Lin and Guicai Li (2010), "Industrial Clustering and Technological Innovation in China: New evidence from the ICT industry in Shenzhen," Environment and Planning A 42(8), pp. 1987-2010.

Wang, Jiamei (2012), “Government to Expand Off-exchange Trading," Global Times August 6 2012, available at: http://english1.people.com.cn/90778/7899283.html, accessed 23 August 2012.

Wang, Jici (1999), "In Search of Innovativeness: The case of Zhong'guancuncun," in Edward, J. Malecki and Päivi Oinas (eds.) Making Connections: Technological learning and regional economic change, Aldershot: Ashgate Publishing Company, pp. 205-230.

Wang, Jici and Jixian Wang (1998), "An Analysis of New-tech Agglomeration in Beijing: A new industrial district in the making?," Environment and Planning $A$ 30(4), pp. 681-701.

Wang Xing (2011), "High-tech Science Park gets Big Boost," China Daily 9 May 2011, available at: http://www.chinadaily.com.cn/bizchina/201105/09/content_12468350.htm, accessed 23 August 2012.

Webster, Andrew and Henry Etzkowitz (1998), "Toward a Theoretical Analysis of Academic-Industry Collaboration," in Henry Etzkowitz, Andrew Webster and Peter Healey (eds.) Capitalizing Knowledge, Albany: State University of New York Press, pp. 47-71.

Westhead, Paul (1997), “R\&D 'Inputs' and 'Outputs' of Technology-based Firms Located on and off Science Parks," R and D Management 27(1), pp. 45-62.

Westhead, P. and D.J. Storey (1995), "Links Between Higher Education Institutions and High Technology Firms," Omega, International Journal of Management Society 23(4), pp. 345-360.

Whiting, Susan H. "Contract Incentives and Market Discipline in China's Rural Industrial Sector," (1996) in John McMillan and Barry Naughton (eds.) Reforming Asian Socialism: The growth of market institutions, Ann Arbor: The University of Michigan Press, pp. 63-110.

Williamson, John (1990), "What Washington Means by Policy Reform," in John Williamson (ed.) Latin American Adjustment: How much has happened?, Washington DC: The Institute for International Economics, pp. 5-20.

Williamson, Oliver E. (2000), "The New Institutional Economics: Taking stock, looking ahead," Journal of Economic Literature 38(3), pp. 595-613.

Williamson, Oliver E. (1985), The Economic Institutions of Capitalism, New York: The Free Press. 
Wong, Siu-Wai and Bo-sin Tang (2005), "Challenges to the Sustainability of 'development zones': A case study of Guangzhou Development District, China," Cities 22(4), pp. 303-316.

World Bank and Development Research Center of the State Council, the People's Republic of China (2012), China 2030: Building a Modern, Harmonious, and Creative High-Income Society, Washington DC: The World Bank.

World Bank (2012a), World Development Indicators, available at:

http://data.worldbank.org/indicator, accessed 28 September 2012.

World Bank (2012b), Worldwide Governance Indicators, available at:

http://info.worldbank.org/governance/wgi/index.asp, accessed 19 April 2012.

World Bank (1996), World Development Report 1996: From plan to market, New York: Oxford University Press.

Xinhua (2006a), “China Outlines Strategic Tasks for Building Innovation-Oriented Country," People's Daily Online 9 January 2006, available at: http://english.peopledaily.com.cn/200601/09/eng20060109_233967.html, accessed 2 December 2012.

Xinhua (2006b), “China Strives to be Science Power," Chinese Government's Official Web Portal, available at: http://english.gov.cn/2006-02/09/content_184335.htm, accessed 2 December 2012.

Yang, Chih-Hai, Kazuyuki Motohashi and Jong-Rong Chen (2009), "Are New Technology-based Firms Located on Science Parks Really More Innovative? Evidence from Taiwan," Research Policy 38(1), pp. 77-85.

Yang, Lei (2006), "Firms Join Stock Trading System," China Daily January 18, 2006, available at: http://english.gov.cn/2006-01/18/content_162292.htm, accessed 22 August 2012.

Yeung, Yue-man, Joanne Lee and Gordon Kee (2009), “China's Special Economic Zones at 30," Eurasian Geography and Economics 50(2), pp. 222-240.

Yuan, Yiming, Hongyi Guo, Hongfei Xu, Weiqi Li, Shanshan Luo, Haiqing Lin and Yuan Yuan (2010), "China's First Special Economic Zone: The case of Shenzhen," in Douglas Zhihua Zeng (ed.) Building Engines for Growth and Competitiveness in China, Washington: The International Bank for Reconstruction and Development / The World Bank, pp. 55-86.

Zeng, Douglas Zhihua (2010), "How do Special Economic Zones and Industrial Clusters Drive China's Rapid Development?," in Douglas Zhihua Zeng (ed.) Building Engines for Growth and Competitiveness in China, Washington: The International Bank for Reconstruction and Development / The World Bank, pp. 1-53.

Zhang, Jun (2008), China's Economic Growth: Trajectories and Evolving Institutions, United Nations University-World Institute for Development Economics Research Research Paper No. 2008/33.

Zhang, Wei-wei. (2000), Transforming China: Economic Reforms and its Political Implications, New York: St Martin's Press. 
Zhao, Minyuan (2006), "Conducting R\&D in Countries with Weak Intellectual Property Rights Protection,” Management Science 52(8), pp. 1185-1199.

Zhou, Yu (2004), "The Making of an Innovative region from a Centrally Planned Economy: Institutional evolution in Zhongguancun Science Park in Beijing," Environment and Planning A, 37(6), pp. 1113-1134.

Zhou, Yu and Tong Xin (2003), "Innovative Region in China: Interaction between multinational corporations and local firms in a high-tech cluster in Beijing," Economic Geography 79(2), pp. 129-152.

\section{Chinese-language}

Beijing Municipal Government Guidance for Further Strengthening Zhongguancun Science and Technology Park [2005], Beizhengfa, No. 22, available at: http://www.zgc.gov.cn/zcfg/zgckjyqxgxzfgzcwj1/24384.htm, accessed 13 December 2012.

Beijing Municipal Government Implementation Measures for the Provisional Regulations for the Beijing City New-Technology Industrial Development Experimental Zone [1998], Beizhengfa, No. 57, available at: http://www.lawlib.com/law/law_view.asp?id=19798, accessed 8 December 2012.

Beijing Municipal Government Provisional Measures for the Determination of NewTechnology Industries within Beijing City New-Technology Industrial Development Experimental Zone [1988], Beijingshi zhengfu, available at: http://www.lawlib.com/law/law_view.asp?id=19767, accessed 8 December 2012.

Beijing Municipal Government Request for Instructions on Implementing the Science and Education National Invigoration Strategy and Speeding up the Construction of Zhongguancun Science and Technology Park [1999], Jingzhengwen No. 35.

Beijing Municipal Government Regulations for Zhongguancun National Innovation Demonstration Zone [2010], No. 12, available at:

http://zhengwu.beijing.gov.cn/fggz/bjdffg/t1146157.htm, accessed 17 September 2012.

Beijing Municipal Government Regulations for Zhongguancun Science and Technology Park [2000], No. 25, available at: http://www.bjdch.gov.cn/n1569/n2458434/n2462161/2573918.html, accessed 17 September 2012.

Beijing Pindao (2004), Haigui, haigui, Zhongguancun guiguo liuxuesheng chuangye jingying saomiao (The cream of the crop students return from study abroad and become entrepreneurs in Zhongguancun), Beijing Xinhua Net, 13 October 2004, http://www.bj.xinhuanet.com/bjpd_djzgc/2004-10/13/content_3022656.htm, accessed 9 December 2012.

Beijing Qingnian Bao (2002), Zhongguancun sannian dabian yang 36 wan "congming jun" zhadui cun li taojin (Zhongguancun Big Changes in Three Years: 360,000-strong "Intelligent Army" gathers in Zhongguancun to try to make a fortune), Xinhua Net, 20 June 2002, http://news.xinhuanet.com/newscenter/200206/20/content_448829.htm, accessed 9 December 2012. 
China Customs Zhongguancun Website, available at:

http://beijing.customs.gov.cn/tabid/30369/MoreModuleID/66844/MoreTabID/2 9807/Default.aspx, accessed 10 December 2012.

Fan, Hexiang (2006), Keji chuangxin juji Zhongguancun dang zhongyang, guowuyang dui Zhongguancun de xin yaoqiu (Central Communist Party and State Council New Request to Zhongguancun regarding the Concentration of Science, Technology and Innovation in Zhongguancun), Beijing Observation 2006-1, available at: http://210.73.78.72/bjgc/BJGCTEXT/200601/20060104.htm, accessed 9 December 2012.

Gu, Yue, [xin zhongguo dang'an] "huoju jihua" guowuyuan pizhun jianli guojia gaoxin jishu chanye kaifaqu ([New China Archive] "Torch Programme" State Council Approves the Establishment of National High- and New-Technology Industrial Development Zones) Xinhua Net, available at:

http://news.xinhuanet.com/ziliao/2009-11/02/content_12372739.htm, accessed 8 December 2012.

Ministry of Finance, National Development and Reform Committee, Ministry of Commerce, Ministry of Science and Technology Notice on the Approval of the Experimental Proposal on Zhongguancun Modern Service Industry [2011], Caijianhan, No. 32, available at:

http://zhengwu.beijing.gov.cn/zwzt/zgcxdfwy/zcwj/t1195687.htm, accessed 16 December 2012.

Ministry of Finance Notice of Trial Policy on Tax Deductions for Research and Developments Expenses in Zhongguancun National Innovation Demonstration Zone [2010], Caishui, No. 81, available at:

http://www.shui5.cn/article/31/46868.html, accessed 16 December 2012.

Ministry of Finance Notice of Trial Policy on Tax Deductions for Staff Training Expenses relating to Zhongguancun National Innovation Demonstration Zone [2010], Caishui, No. 82, available at:

http://www.zgc.gov.cn/“1+6"zc/ssyhsdzc/xgzcwj_1+61/69362.htm, accessed 16 December 2012.

Ministry of Science and Technology Notice on the Publication of "Measures and Qualifying Conditions for High- and New-Technology Industries in National Highand New-Technology Industrial Development Zones" [2000], guokafa huozi, No. 324, available at: http://www.gov.cn/gongbao/content/2001/content_60688.htm, accessed 8 December 2012.

State Council Notice Concerning the Approval of National High- and NewTechnology Industrial Development Zones and Related Policy Regulations [1991], Guofa, No. 12, available at: http://www.law-lib.com/law/law_view.asp?id=7431, accessed 16 November 2012.

State Council Provisional Regulations of the Beijing Experimental Zone for the Development of New-Technology Industries [1988], Beizhengfa, No. 49, available at: http://www.law-lib.com/law/law_view.asp?id=49404, accessed 17 September 2012.

State Council Reply Agreeing to Support Zhongguancun Science and Technology Park to be Established as a National Innovation Demonstration Zone [2009], 
Guohan, No. 28, available at: http://www.zgc.gov.cn/gjzzcxsfq/46577.htm, accessed 17 September 2012.

State Council Reply to "Request for Instructions on Implementing the Science and Education National Invigoration Strategy and Speeding up the Construction of Zhongguancun Science and Technology Park" [1999], Guohan, No. 45.

Zhang, Yingchun (2008), 20 nian fazhan: Zhongguancun chengwei zhongguo de chuangxin zhongxin (20 Years of Development: Zhongguancun becomes China's innovation centre), available at ZGC website:

http://www.zgc.gov.cn/yqxw/35337.htm, accessed 22 August 2012.

Zhao, Wenyan (ed.) (1998), Zhongguancun shinian zhilu: Beijing shi xin jishu chanye kaifa shiyan qu huigu yu zhanwang (The Ten-year Road of Zhongguancun: A review and Outlook on Beijing Experimental Zone for the Development of New Technology Industries), Beijing: Gaige Chubanshe.

Zhongguancun website (2012), http://www.zgc.gov.cn/sfqgk/55179.htm, accessed 28 August 2012. 